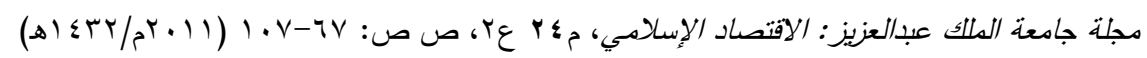
DOI: 10.4197 / Islec. 24-2.2

\title{
صكوك الإجارة الموصوفة في الذمة والمنتهية بالتمليك
}

\section{عبدالله بن محمد العمراني}

أستاذ مشارك - قسم الفقه - كلبة الشريعة- الرياض لعرائ

السستخلص. يبتاول هذا البحث أحكام صكوك الإجارة الموصوفة في

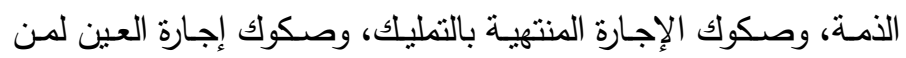

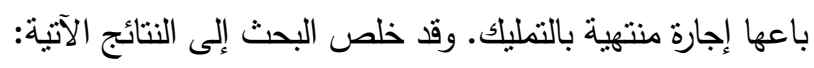
- يجوز إجارة منافع الأعيان الموصوفة في الذمة بشرط توفر شروط الئل السلم فيها.

- يجوز إصدار صكوك الأعيان الموصوفة في الذمة على أساس عقد

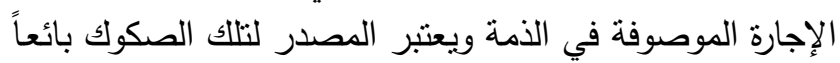

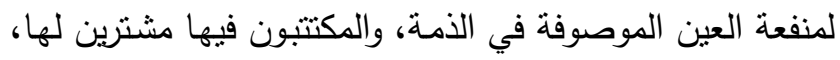
وحصيلة الاكتتاب هي ثمن ثلك المنفعة، ويملك حملة الصكوك فئكي تلك المنافع على الثيوع بغنمها وغرمها. ويشترط أن يتضـمن عقد إصـدار الصـكوك الثـروط الثـرعية لإجارة العين الموصوفة في الذمة. - لا يجوز تداول صكوك ملكية منافع الأعيان الموصـوفة في الذمـة قبل العبل

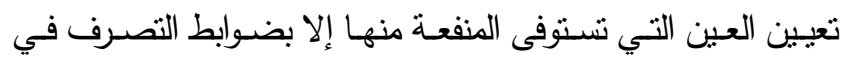

$$
\text { الديون. }
$$

- يجوز إصدار صكوك إجارة منتهية بالتمليك بناء على عقد الإجارة،

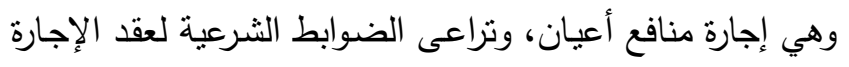

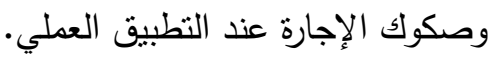


-يجوز تداول صكوك الإجارة المنتهية بالتمليك مـا دامت تمثنل حصـة شائعة في ملكية موجودات الأعيان وفق المعايير والضوابط الثرعية.

اختلف المعاصـرون في حكم إجـارة العين لمـن باعها إجـارة

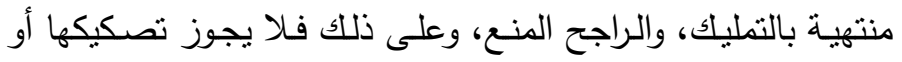

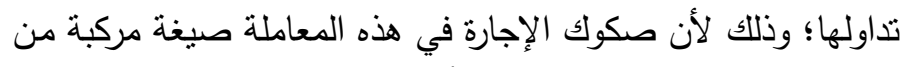

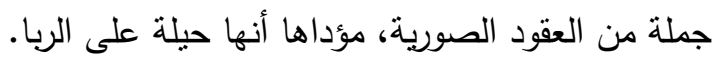

\section{المقدمة}

يسهم هذا الموضوع في تطوير مسيرة الصناعة المالية الإسلامية، وأدوات الاستثمار

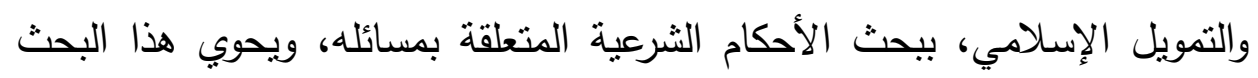

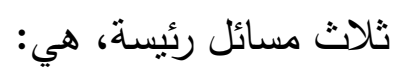

ا ـ صكوك الإجارة الموصوفة فئة في الذمة.

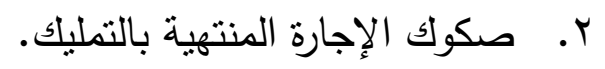

r. صكوك إجارة العين لمن باعها إجارة منتهية بالتمليك.

وسيتم تتاول كل مسألة من المسائل السابقة من ناحيتين:

$$
\text { ثأولاً: حكمًا: إصدار الصكوك. }
$$

وقد كانت هذه المسائل مما أوصى المجمع الفقهي الإسلامي الدولي في دورة سابقة بأن يجري فيها مزيد بحث. وتعد من المسائل الفقهية الدقيقة والعميقة من الإني حيث تصورها، والخلوص إلى حكم فقهي فيها. وقد اجتهدت وسعي في هذا البحث وفق المنهج العلمي في بحث المسائل الفقهية.

\section{المبحث الأول: صكوك الإجارة الموصوفة في الأمة}

المسألة الأولى: تعريف صكوك الإجارة الموصوفة في الأمة

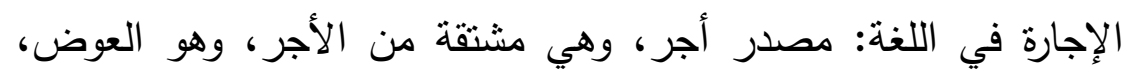


والجزاء على العمل (').

وفي الاصطلاح: تمليك المنفعة بعوض معلوم(؟). الصكوك في اللغة: مادة الكلمة تدور على معنيين:

المعنى الأول: الضرب بشدة؛ جاء في معجم مقاييس اللغة:(؟)((الصاد، والكاف أصل يدل على تلاقي شيئين بقوة وشدة ...). المعنى الثاني: الكتاب، جاء في لسان العرب(ء) (( الصك: الكتاب فارسيّ معرب)). وفي المغرب(ْ): (وأما الصك لكتاب الإقرار بالمال أو غيره فمعرّ)).

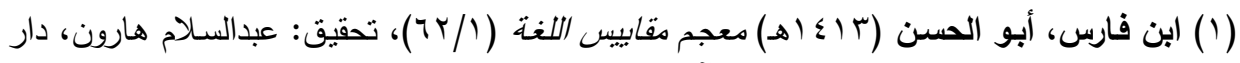

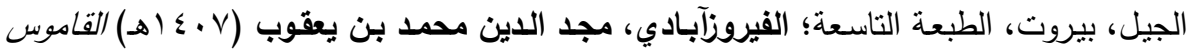

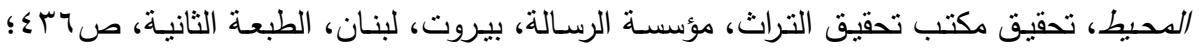

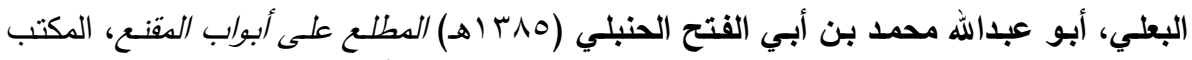

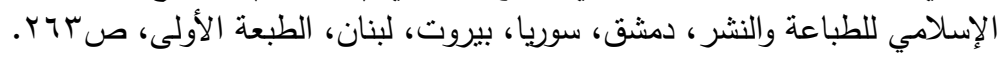

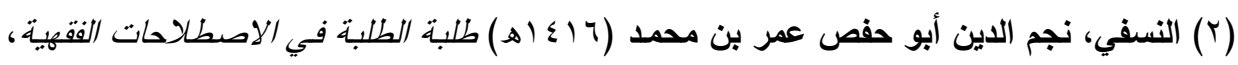

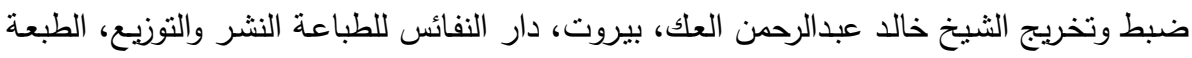

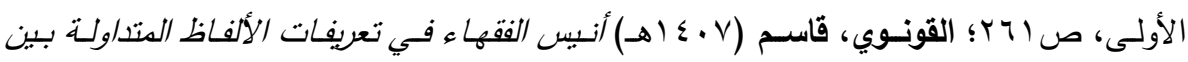

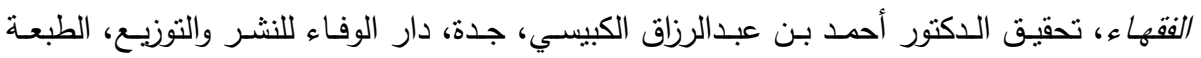

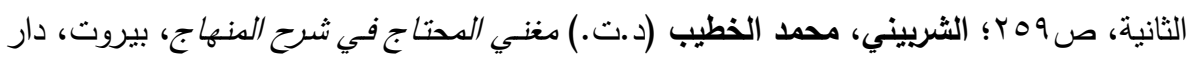

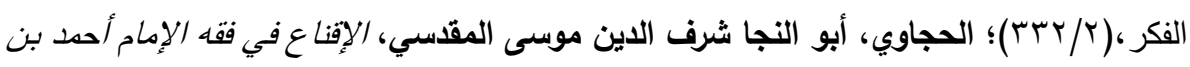

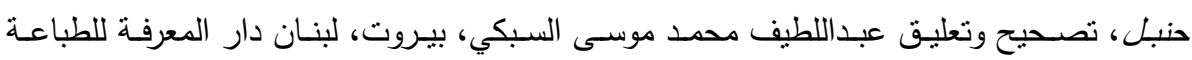

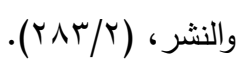

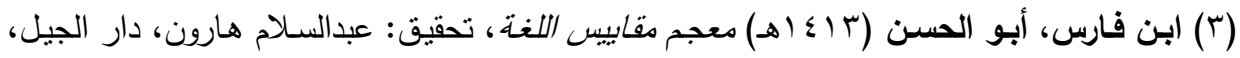

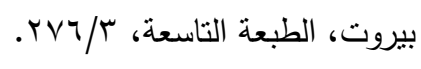

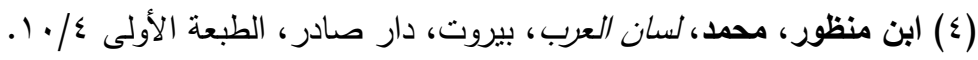

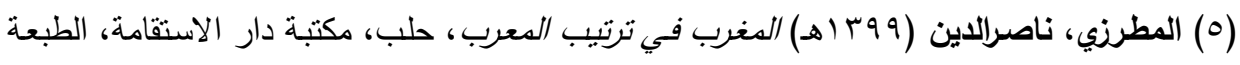

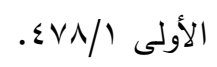


وجاء تعريف صكوك الاستثمار اصطلاحًا في معايير هيئة المحاسبة(؟)

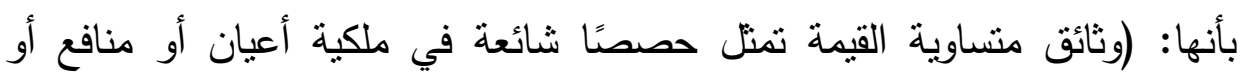
خدمات أو في موجودات مشروع معين أو نشاط استثماري خاص، وذلتك بعد تحصيل قيمة الصكوك وقفل باب الاكتتاب وبدء استخدامها فيما أصدرت من أجله).

\section{• تعريف الإجارة الموصوفة في الأمة}

قبل البدء في تعريف الإجارة في الذمة تحسن الإشارة إلى أن الإجارة الواردة على منافع الأعيان نوعان:

النوع الأول: الإجارة الواردة على منفعة عين معينة، سواء أعينت بالإشارة أم أم المعاء

بالوصف، ويتعلق حق المستأجر بمنفعة العين المعينة المعقود عليها لا سواها. النوع الثاني: الإجارة الواردة على منفعة عين موصوفة في الذمة، مثل أن

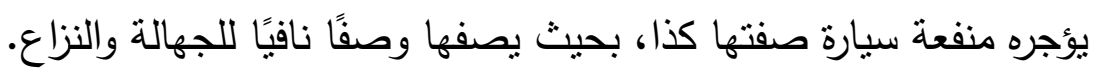
ويتعلق حق المستأجر فيها بمنفعة عين موصوفة في ذمة المؤجر لا بعين معينة، ولا بعمل في ذمة المؤجر ·

\section{تعريف الإجارة الموصوفة في الأمة}

هي الإجارة التي ترد على منفعة متعلقة بذمة المؤجر كاستنجار دابة أو سيارة

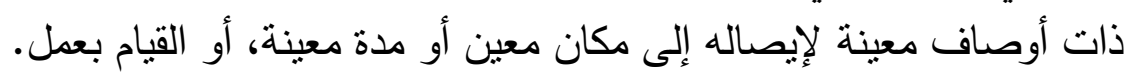
وعرفت الإجارة الموصوفة في الذمة بأنهال('): (بيع منافع مستقبلية بثمن حال) ويشير الفقهاء في تعليلاتهم إلى أنها سلم في المنافع، وأنها الإجارة التي ترد على بلى بانه

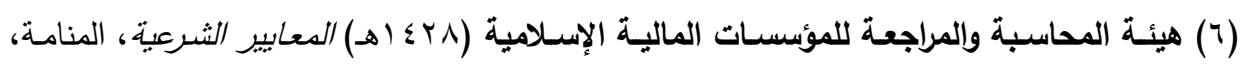
ص. آس.

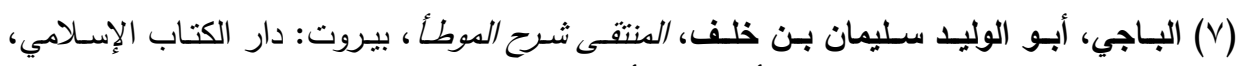

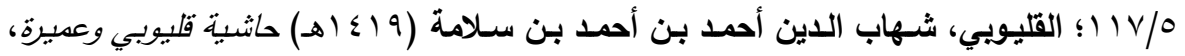

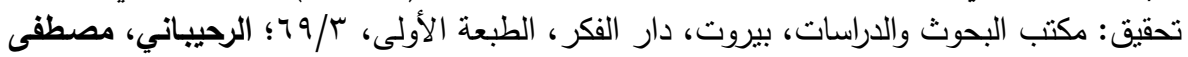

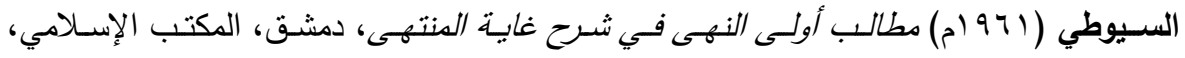


منفعة عين متعلقة بذمة المؤجر ، كاستئجار دابة ذات أوصاف معينة، لإيصاله إلى معان مكان معين، أو مدة معينة، أو القيام بعمل معين. وتعرف صكوك ملكية منافع الأعيان الموصوفة في الذمة بأنهان أنها (وثائق

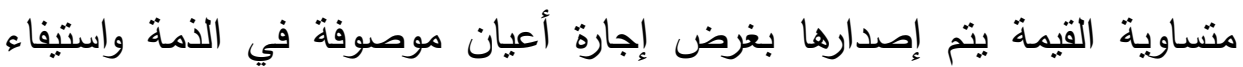

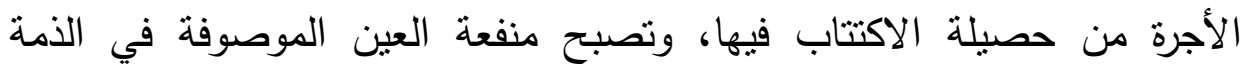

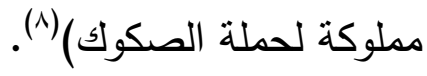
المسألة الثانية: حكم إجارة العين الموصوفة في الأمة اختلف الفقهاء في حكم العين الموصوفة في الذمة على قولين: القول الأول: عدم جواز إجارة منافع الأعيان الموصوفة في الذمة وهو مذهب الحنفية) (9) القول الثاني: جواز إجارة منافع الأعيان الموصوفة في الذمة وهو مذهب

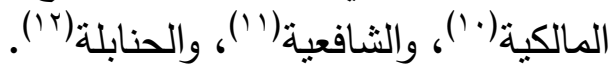
أدلة القول الأول الاليل الأول: أن المنافع لا تعتبر أموالاً، لأن المال ما بمكن ادخاره لوقت

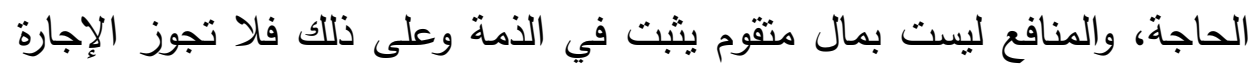
الموصوفة في الذمة(r').

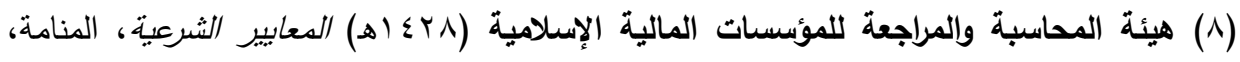
ص. الا

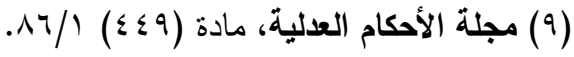
(· (1) الاسوفي، محمد عرفة (د.ت.) حاشية الدسوقي على الثرح الكبير، تحقيق: محمد عليش، دار

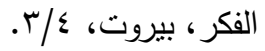

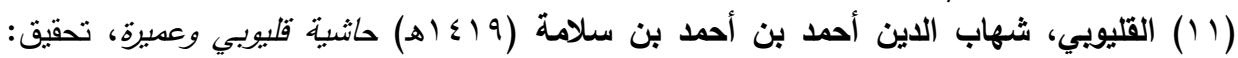

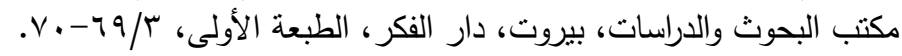

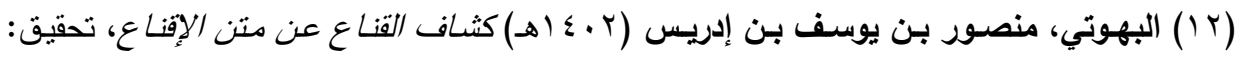

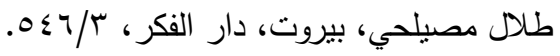

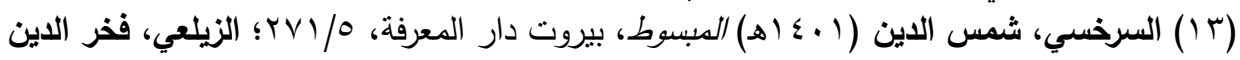

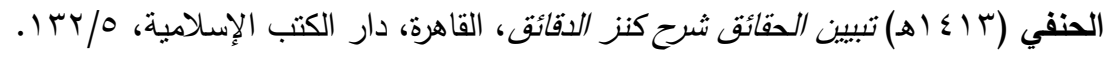


لا يسلم بأن المنافع لا تعتبر أموالاً، بل المنافع أموال تصح المعاوضة عليها،

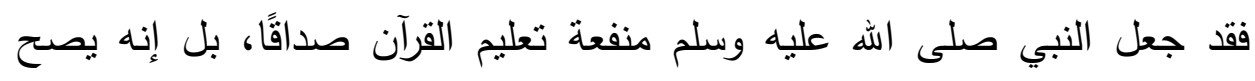

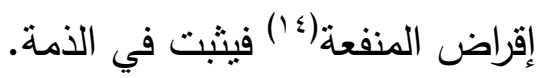

جاء في الاختيارات الفقهية(10): ((يجوز قرض المنافع، منل أن يحصد معه يومًا ويحصد معه الآخر يومًا، أو يسكن دارًا ليسكن الآخر بدلها)).

الاليل الثاني: أنّ من شروط صحة عقد الإجارة كون المؤجر معينًا (1)، وعليه فلا يجوز ورود العقد على منفعة موصوفة في الذمة غير متعلقة بذات معينة. المناقثة: يناقش بأن هذا الاثتراط يحتاج إلى دليل، وهو ينافي أن الأصل في العقود المالية الحل والإباحة.

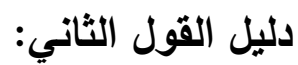
استذلوا بأن إجارة العين الموصوفة في الذمة من باب السلم في المنافع. وعليه فإن جواز إجارة منافع الأعيان الموصوفة في الذمة منوط بتوفر شروط

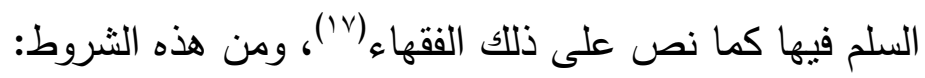

(\{ () العمراني، عبدالله بن محمد (YY \& اهـ) الدنفعة في القرض، الرياض، دار ابن الجوزي، ص

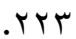
(10) البطي، أحمد (د.ت.) الاختيارات الفقهية الرياض، مكتبة الرياض الحديثة، صابـا.

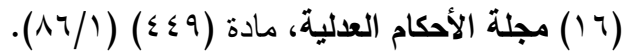

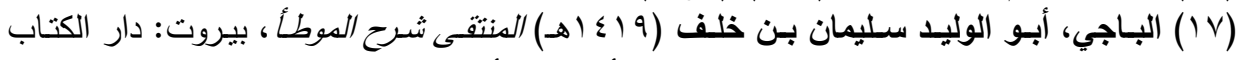

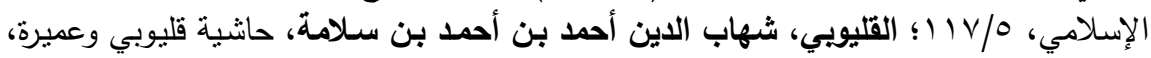

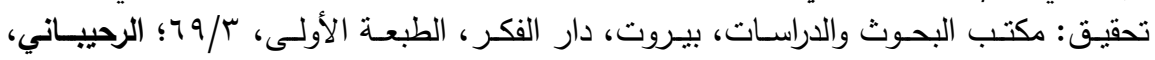

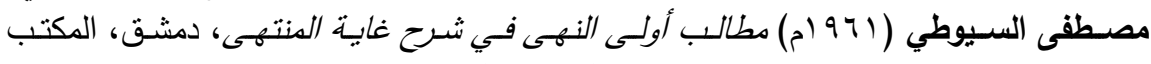

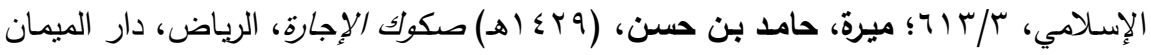


( ) أن تكون العين المؤجرة مما ينضبط بالوصف.

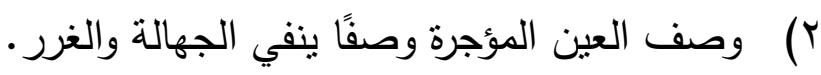
ب) تعجيل تسليم الأجرة - على الخلاف الآتي:

المسألة الثالثة: حكم اشتراط تسليم الأجرة في مجلس العقد في الإجارة الموصوفة في الأمة:

اختلف جمهور الفقهاء - القائلون بجواز الإجارة في الذمة - في حكم اشتراط تسليم الأجرة في مجلس العقد على ثلاثة أقوال:

القول الأول: أنه يجب لصحة الإجارة الموصوفة في الذمة قبض المؤجر الأجرة في مجلس العقد إلا إذا شرع المستأجر باستيفاء المنفعة - كما لو ركب المستأجر السيارة الموصوفة في طريقه إلى المكان المشترط أن تحمله إليه، فيجوز عندئذٍ تأخير الأجرة. وهذا قول المالكية(1).

القول الثاني: أنه بشترط في الإجارة الموصوفة في الذمة قبض المؤجر الأجرة في مجلس العقد منل السلم. وهذا قول الشافعية(9).

القول الثالث: أن الإجارة الموصوفة في الذمة إذا عقدت بلفظ السلم والسلف فإنه يثترط لصحة إجارة الذمة عندئذٍ تسليم الأجرة في مجلس العقد. وأما إذا لم تعقد بلفظ السلم والسلف فلا يشترط فيها تعجيل الأجرة. وهذا قول الحنابلة(·r).

(1) محمد أبو البركات أحمد الاردير (د.ت.) الشرح الكبير، تحقيق: محمد عليش، بيروت، دار الفكر، .r/s

(9 (1) الثربيني، محمد الخطيب، (د.ت.) مغني الدحتاج في شرح الدنهاج، بيروت، دار الفكر ، 的

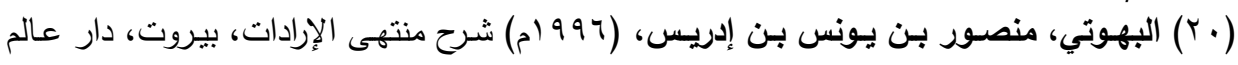

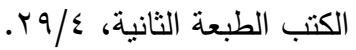


دليل القول الأول: أن شروع المستأجر في استيفاء المنفعة ينفي بيع المؤخر بالمؤخر ، حيث أن قبض أوائل المنفعة كقبض أواخرها فارتفع المانع من التأخير (بr).

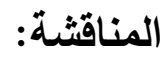

يمكن أن يناقش بأنه بمجرد استيفاء المنفعة لم تعد موصوفة في الذمة وإنما تكون متعيّنة حينئذٍ.

دليل القول الثاني: أن الإجارة الموصوفة في الذمة سلم في المنافع، فكانت

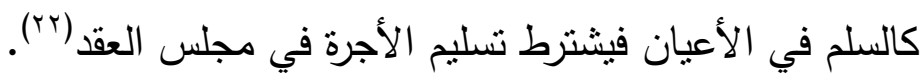
دليل القول الثالث: أن الإجارة في الذمة إذا عقدت بلفظ السلم فإنها تكون سلمًا في المنافع وأما إذا لم تعقد بلفظ السلم فإنها لا تكون سلمًا في هذه الحالة فلا يلزم تسليم الأجرة حينئذِ(r). وقد رجح هذا القول بعض المعاصرين(£) بناءً على أن الإجارة وإن كان لها شبه بالسلم من بعض الوجود فليست بسلم من كل وجه، وبالتالي فلا تتطبق عليها

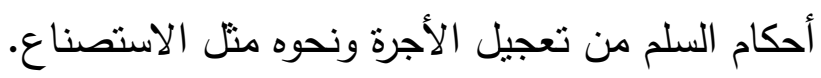

(Y) محمد أبو البركات أحمد الدردير (د.ت.) الشرح الكبير، تحقيق: محمد عليش، بيروت، دار الفكر (Y) 政

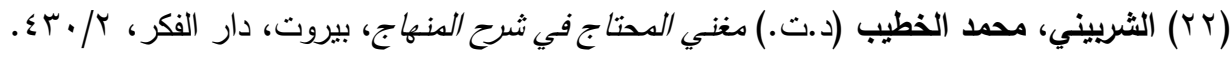

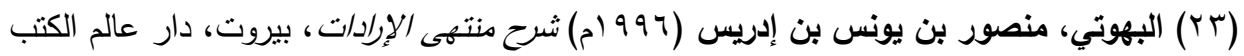

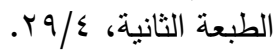

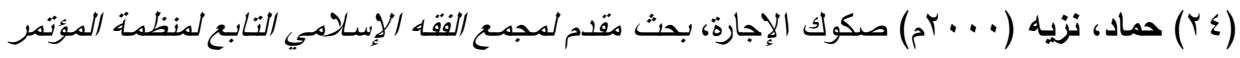

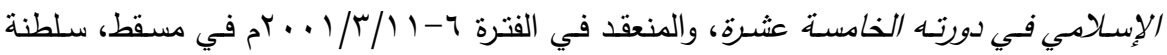

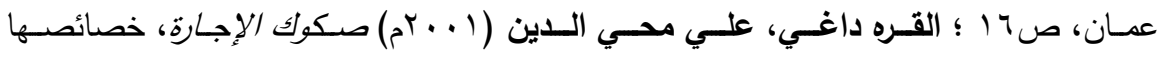

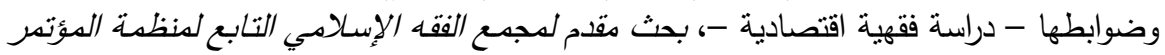

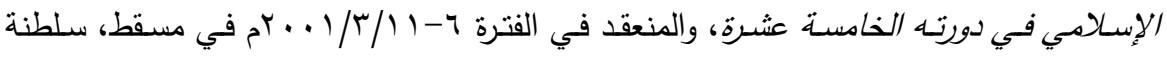

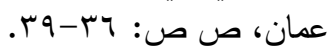


الترجيح:

بالتأمل في أدلة الأقوال الثلاثة، والبناء الفقهي لهذه المسألة وهو جواز الإجارة الموصوفة في الذمة بناءً على أنها سلم في المنافع، فإن الباحث يميل إلى القول الثاني خاصة وأن القول الثالث ليس واضحًا بشكل دقيق؛ لأن العبرة في العقود بالمقاصد والمعاني لا بالألفاظ والمباني، ولعل مؤدى قول الحنابلة أنها إذا عقدت واقعًا حسب حقيقة العقد لا باللفظ فقط فيكون القول وجيهًا حينئذٍ. وعلى كلٍ فإن المسألة ما زالت بحاجة إلى تأمل خاصة وأنه قد يقال: إن الإجارة قد لا تتفق مع البيع من كل وجه في الأحكام فلا يشترط حينئذٍ تسليم الأجرة في المجلس والله أعلم.

المسألة الرابعة: حكم إصدار صكوك الإجارة الموصوفة في الأمة: بناءً على ما سبق من جواز الإجارة الموصوفة في الذمة فإنه يجوز إصدار صكوك الأعيان الموصوفة في الذمة على أساس عقد الإجارة الموصوفة في الذمة وبعتبر المصدر لتلك الصكوك بائعًا لمنفعة العين الموصوفة في الذمة، والمكتتبون فيها مشترين لها، وحصيلة الاكتتاب هي ثمن تلك المنفعة، ويملك حملة الصكوك تلك المنافع على الثيوع بغنمها وغرمها (ro). وبشترط أن يتضمن عقد إصدار الصكوك الشروط الشرعية لإجارة العين الموصوفة في الذمة ومنها: وصف العين محل العقد وصفًا نافيًا للجهالة، وأن تكون العين الموصوفة مما يمكن ضبطه بالصفة، وتحديد موعد استيفاء منفعة العين المؤجرة، ومدتها، ومقدار الأجرة وطريقة الدفع ونحو ذلك. كما يحسن التتبيه إلى أن هذا من حيث التأصيل الفقهي، ولابد للجواز من 
توفر الضوابط الشرعية حين التطبيق في الواقع.

المسألة الخامسة: حكم تداول صكوك ملكية منافع الأعيان الموصوفة في الأمة: اختلف المعاصرون في هذه المسألة على قولين:

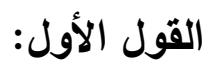

لا يجوز تداول صكوك ملكية منافع الأعيان الموصوفة في الذمة قبل تعبين العين التي تستوفى المنفعة منها إلا بضوابط التصرف في الديون. وهذا ما تبناه قرار هيئة المحاسبة والمراجعة(Tr).

القول الثاني: يجوز تداول صكوك ملكية منافع الأعيان الموصوفة في الذمة مطلقًا. وهذا قول لبعض المعاصرين (rv).

أدلة القول الأول: - ألقا

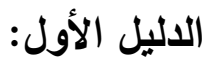

لا يجوز تداول صكوك ملكية منافع الأعيان الموصوفة في الذمة؛ لأن قيمة

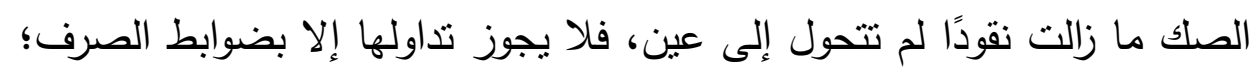
لأن ذللك من قبيل بيع النقد بالنقد (r^).

(YT) هيئة المحاسبة والمراجعة للمؤسسات المالية الإسلامية (1) (اهـ) الدعايير الثرعية، المنامة، صو الب.

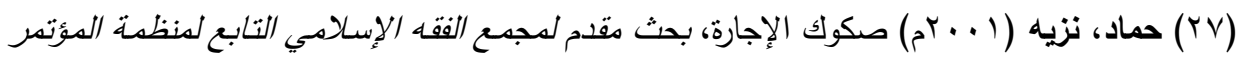

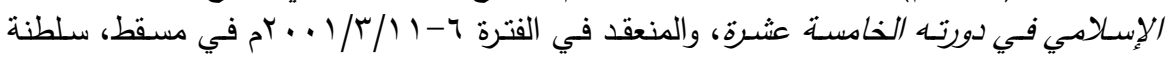

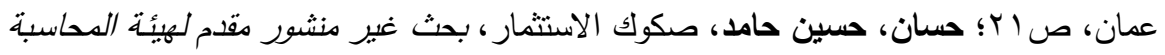

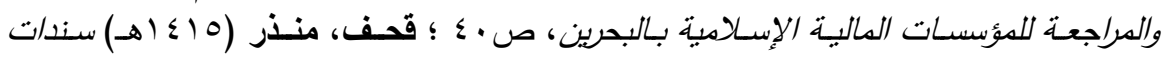

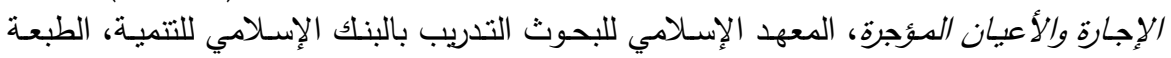

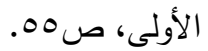

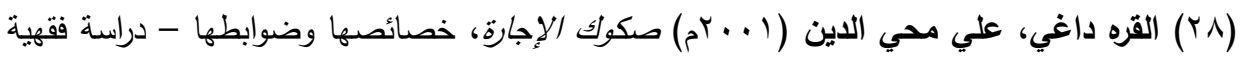

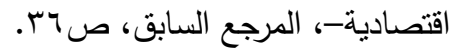


نوقش: بأنه لا بسلم بأن تداول صكوك ملكية منافع الأعيان الموصوفة من قبيل بيع النقد بالنقد، وإنما هو بيع منفعة بنقد، وذللك لأن إجارة الموصوف في الذمة إنما تثبت المنفعة المعقود عليها في ذمة المؤجر، وقد نص الفقهاء في إجارة الأعيان الموصوفة في الذمة بأن المنفعة إنما تتعلق بذمة المؤجر لا بعين أو محل. وعليه فلو أجر منفعة دابة موصوفة في الذمة فهلكت وجب عليه أن بعطيه أخرى مكانها لأن حق المستأجر إنما تعلق بذمة المؤجر لا بعين معيّنة. وعليه فإنه وإن تعيّنت العين الموصوفة في الذمة وشرع المستأجر في استيفاء المنافع الموصوفة في الذمة منها فإن حق المستأجر لا يتعلق بعينها وإنما يتعلق بذمة المؤجر، وهو ما يوكد أن المستأجر قد استحق منفعة معلومة منذ العقد وإن لم تتعيّن العين التي تستوفى منها تلك المنفعة(99). الإجابة: يمكن أن يجاب بأن المنظور إليه ليس الضمان حال الهلاك من عدمه، بل لأنها أصبحت دينًا في الأمة ودين السلم لا يجوز بيعه قبل قبضه. الاليل الثاني: أن تأجير المنافع الموصوفة في الذمة يؤدي إلى بيع الدين بالدين؛ لأن المنفعة إذا كانت تستوفى من موصوف في الذمة فهي في حكم الدين؛ فلا يجوز إذًا إصدار الصكوك المتداولة بشأنها.

المناقشة:

نوقش من وجهين:

ا. أن أصحاب هذا القول أجازوا إجارة الموصوف في الذمة، وعليه فإذا جاز للمؤجر أن يؤجر منفعة عين معدومة بالوصف المنضبط مقابل ما بدفعه (Yq) ميرة، حامد بن حسن (Yq) (هـ) صكوك الإجارة، الرياض، دار الميمان للنشر والتوزيع، 
المستأجر من أجرة، فما المانع أن يقوم ماللك الصك بإعادة تأجير هذه المنفعة

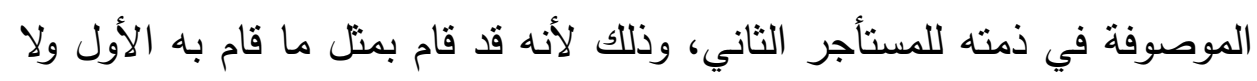
فرق، فلماذا أجزتموه للأول ومنعتموه للثناني(·r). الإجابة: يجاب بأن المنفعة الموصوفة في الذمة أصبحت دينًا متل دين السلم

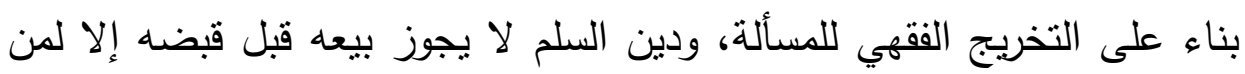
هو عليه بمثل الثن أو دونه لا أكثر حالاً.

وما ذكر من عدم المانع بمكن قبوله بناءً على جواز السلم الموازي دون ربط بين العقدين وفق أحكام السلم والسلم الموازي. r. أن بيع الدين بالدين ليست كل صوره ممنوعة اتفاقًا، وإنما محل الاتفاق

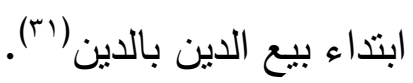
الإجابة: يجاب بأن مسألة بيع دين السلم قبل قبضه هي من صور بيع الدين المحرمة - باستثناء بعض الصور - -.

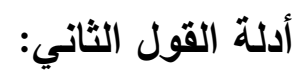
الاليل الأول: تداول صك ملكية منفعة عين موصوفة في الذمة إنما هو حوالة للوفاء بالالتزام، وليس بيعًا لنفس المنفعة الموصوفة (rr).

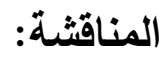

نوقش: بأنَّ العبرة في العقود بالمقاصد والمعاني لا بالألفاظ والمباني، فحامل

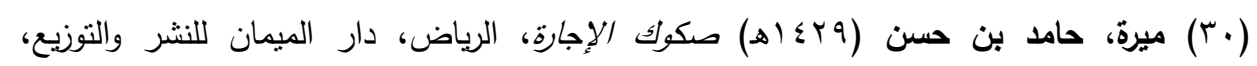

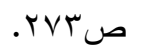

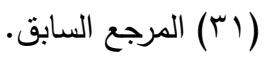

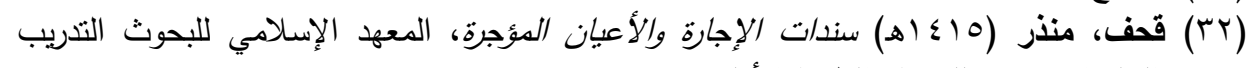

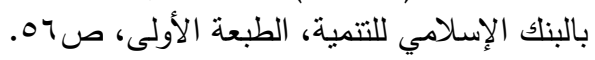


الصك إنما قام ببيع المنفعة الموصوفة بدليل أخذه عوضًا عن ذلك، وأما تسميته حوالة بالوفاء، فلا يغيّر من حقيقة العقد شيئًا (rr).

الاليل الثاني: إجارة عين موصوفة في الذمة سلم في المنافع، وقد أجاز بعض المالكية، وشيخ الإسلام ابن تيمية، وابن القيم: التصرف في المسلم فيه قبل قبضنه على تفصيل عندهم.

وعليه فتجوز إعادة تأجير المنفعة الموصوفة في الذمة قبل تعيّن العين محل الاستيفاء، وهو تداول صك ملكية منفعة العين الموصوفة في الذمة (عَr). المناقشة: يمكن أن يناقش بأنه يلزم من إقرارهم بأنها سلم في المنافع عدم الجواز إلا في الحالة المسنثاة على التفصيل الذي ذكره شيخ الإسـام وغيره بحيث لا يكون هناك زيادة على الدين، وليس المحذور هو عدم تعيّن العين.

الاليل الثالث: القياس على صكوك ملكية منافع الأعيان المعينة، فيجوز قياسًا عليها تداول صكوك ملكية منافع الأعيان الموصوفة في الذمة ولا فرق ؛ لأن المنافع المعلومة قابلة للبيع بعقد الإجارة، وكذلك التداول سواء أكان عقد الإجارة الأول واردًا على عين معيّنة أم موصوفة في الذمة، إذ لا فرق بين كون المنفعة التي نرد عليها الملكية بعقد الإجارة متعلقة بعين محددة بذاتها، وبين كونها متعلقة

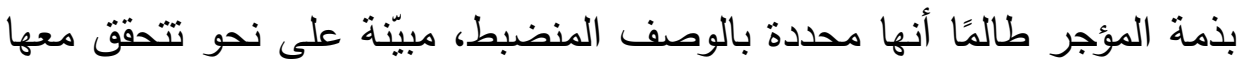
المعلومية المشترطة لصحة بيعها وتداولها (ro).

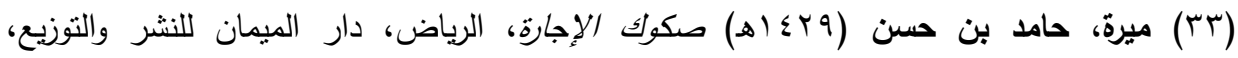
ص ص ص (؟) حسان، حسين حامد (د.ت.) صكوك الاستثمار، بحث غير منشور مقدم لهيئة الدحاسبة

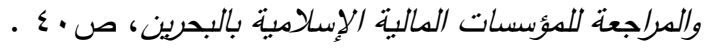

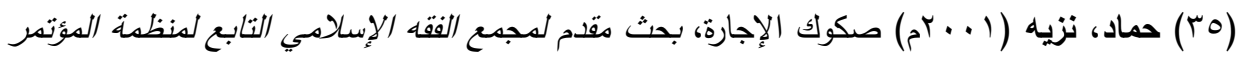

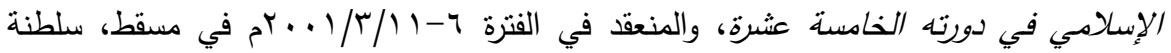


المناقشة: يمكن أن يناقش بأن القياس مع الفارق؛ لأن الإجارة على عين

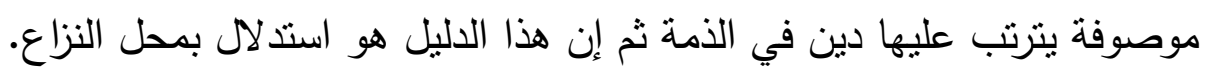

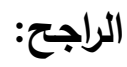

بعد عرض القولين في المسألة وأدلة كل قول والمناقثات الواردة ينتين واله أعلم - رجحان القول الأول لظهور أدلته ومناقثة أدلة القول الثاني.

إلا أنه يمكن القول بالجواز بناءً على أحكام السلم والسلم الموازي دون ربط بين العقدين. لكن يؤخذ في الاعتبار مدى صلاحية هذا التصرف في التناء لنطبيق العملي ومدى توفر منافع مساوية للمنافع الأولى خاصة أن السلم في السلع المعينة أكثر رغبة بين الناس من السلم في المنافع.

\section{المبحث الثاني: صكوك الإجارة المنتهية بالتمليك}

المسألة الأولى: تعريف الإجارة المنتهية بالتمليك وصورها:

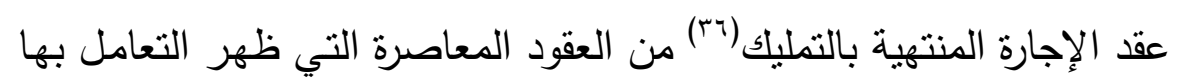

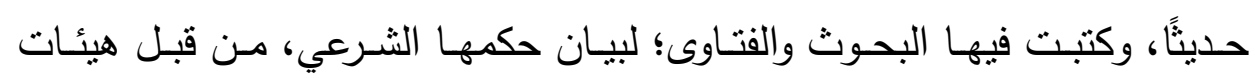
الفتوى، والمجامع الفقهية، والبحوث والرسائل العلمية، وغيرها. وكثبر ممن كتب في هذا العقد اعتىى بييان صوره، وتكييفه الفقهي دون التركيز على استخلاص تعريف له.

( ب؟r) التمليك في اللغة: مصدر ملاّك، أي جطله ماككًا للمال.

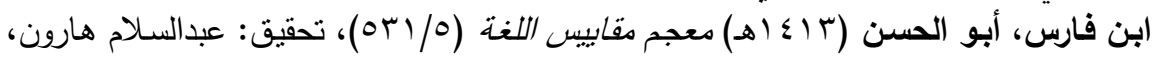

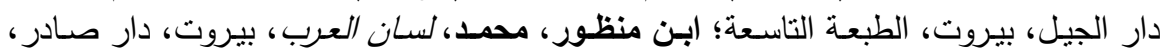

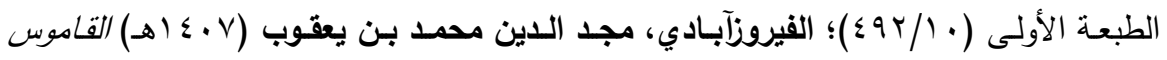

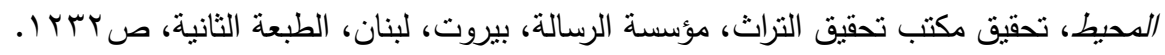
وفي اصطلاح الفقهاء بمعناه اللغوي. 
وفي المقابل عُرف هذا العقد بتعريفات، من أبرزها ما يأتي:

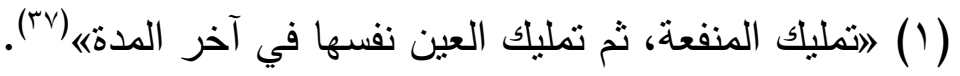
(Y) (التعاقد بين مالك ومستأجر على أن ينتفع المستأجر بمحل العقد بأجرة محددة بأقساط موزعة على مدد معلومة، على أن ينتهي هذا العقد بملك المستأجر

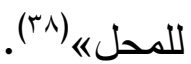

(ب) أن يتفق الطرفان على إجارة شيء لمدة معينـة بأجرة معلومة -قد تزبد

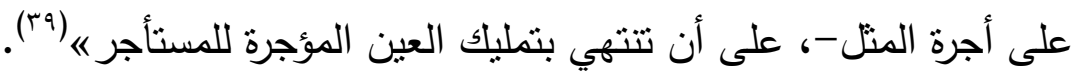
(§) التمليك منفعة عين معلومة، مدة معلومة، يتبعه تمليك للعين على صفة

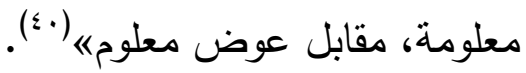

(0) (إجارة يقترن بها الوعد بتمليك العين المؤجرة إلى المستأجر في نهاية

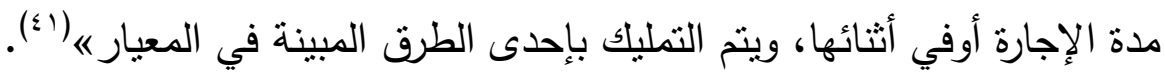
يتبين من خـلال التعريفات السـابقة التعريف بعقد الإجارة المنتهية بالتمليك، وأنه عقد إجارة عين يتبعه تمليك العين للمستأجر والملاحظ على بعض التعريفات السابقة أنها عرفت الإجارة المنتهية بالتمليك حسب الصـيغ المقترحـة لهـا لتكـون شـرعية، كـالتعريف الأخيـر، وبعضــها عرفهـا

(YV)

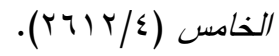

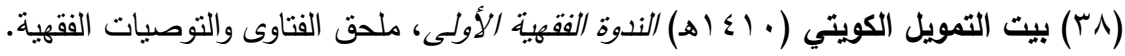

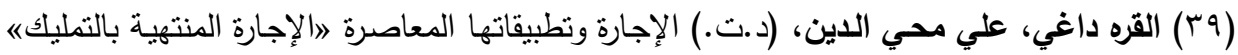

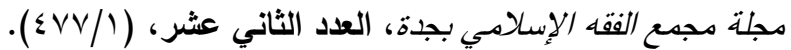

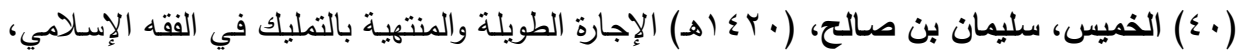

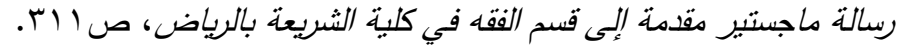

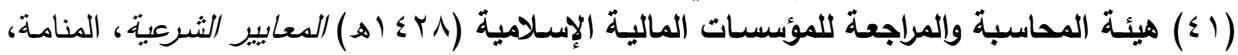


حسب الصيخة المعمول بها كالتعريف الثالث، وباقي التعريفات جاءت عامة شاملة لأغلب الصور على وجه العموم.

\section{صور الإجارة المنتهية بالتمليك}

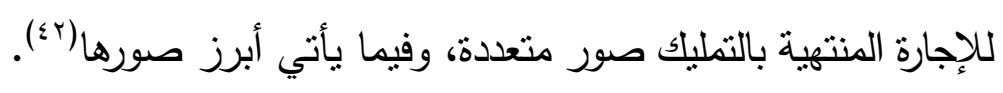
الصورة الأولى: إجارة تتنهي بالتمليك دون دفع ثمن سوى الأقساط الإيجارية. وذلك بـأن يصـاغ العقد على أنه عقد إجـارة ينتهي بتملك الثـيء المؤجر مقابل ثمن يتمثل في المبالغ التي دفعت فعلاً، كأقساط إيجار لهذا الثيء المؤجر خلال المدة المحددة، ويصبح المستأجر مالكًا (أي مشتريًا) للثيء المؤجر تلقائيًا بمجرد سداد القسط الأخير، دون حاجة إلى إبرام عقد جديد. ويمكن أن نتصور صيغة هذا العقد على النحو التالي:

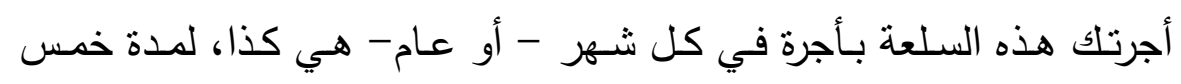

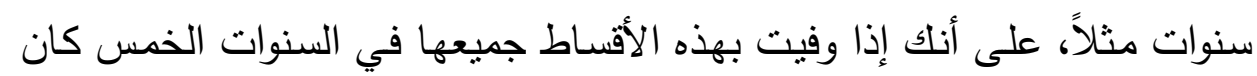
الثيء المؤجر ملكًا للك مقابل ما دفعته من أقساط الأجرة، وقال الآخر قبلت (r؟؛). الصورة الثانية: اقتران الإجارة ببيع الثيء المؤجر بثمن رمزي. وذلك بأن بصساغ العقد على أنسه عقد إجـارة يُمَكِنُ المستأجر مـن الانتفـاع بـالعين المؤجرة في مقابـل أجـرة محددة في مدة محددة للإجـارة، على أن يكون

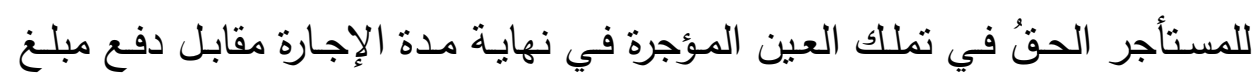
(رمزي) هو كذا.

(r) استبعدت الصور التي ليس لها علاقة بالإجارة المنتهية بالتمليك، أو التي لها علاقة لكنها ليست

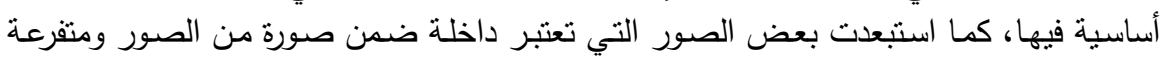
عنها.

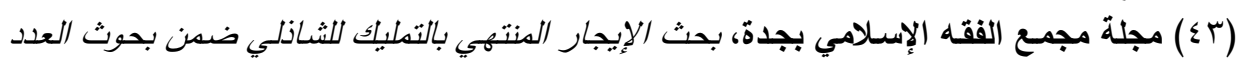

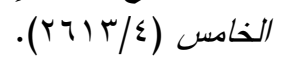


ويمكن أن نتصور صيغة هذا العقد على النحو التالي:

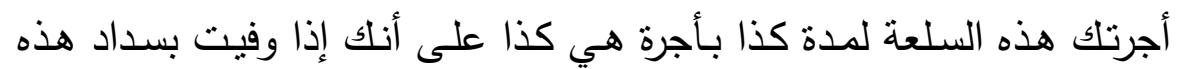
الأقساط خلال هذه المدة بعتلك هذه السلعة - إذا رغبت في ذلك- بثمن (رمزي)

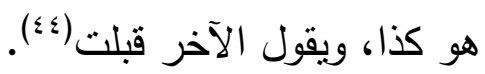

\section{الصورة الثالثة: اقتران الإجارة ببيع الثيء المؤجر بثمن حقيقي.}

وهذه الصـورة مثنل الصـورة الثانيـة إلا أن الثمن هنـا ثمن حقيقي، وذلك بـأن يصاغ العقد على أنه عقد إجارة بمكن المستأجر من الانتفاع بالعين المؤجرة في

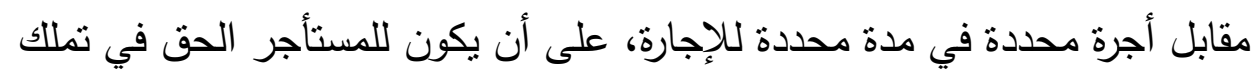
العين المؤجرة في نهاية مدة الإجارة مقابل دفع مبلغ (حقيقي) هو كذا. وصياغة العقد كالصورة الثانية ويكون الثمن حقيقيًا (ه).

\section{الصورة الرابعة: اقتران الإجارة بوعد بالبيع.}

وذلك بـأن يتم الاتفـاق على إجـارة السـلعة، مـع وعد بـالبيع في نهايـة

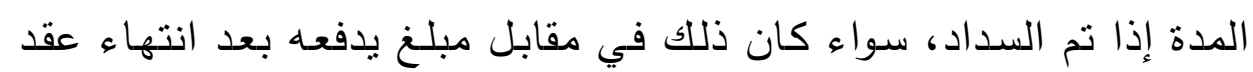

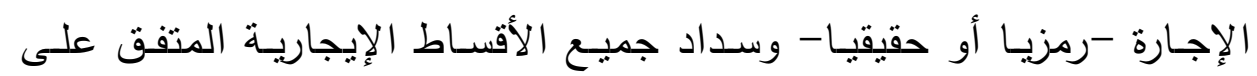
سدادها خلال هذه المدة، أو كانت هذه الأقساط الإيجارية هي ثمن السلعة، الإقة ولم يتفق على دفع شيء آخر، لا رمزي ولا حقيقي. حسب مـا يتفق عليه

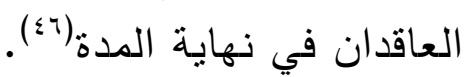

(§ §) مجلة مجمع الفقه الإسلامي بجدة، بحث الإيجار المنتهي بالتصليك للشاذلي ضدن بحوث العدد

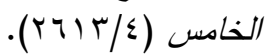

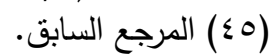

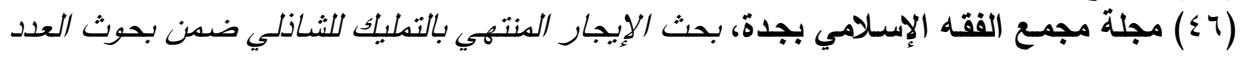

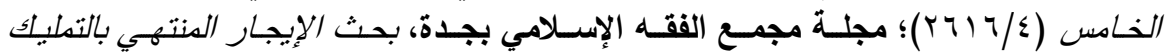

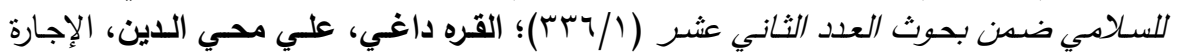
وتطبيقاتها المعاصرة هالإجارة المنتهية بالتمليكي، المرجع السابق. 


\section{الصورة الخامسة: الإجارة المنتهية بالتخيير •}

وهي: اقتران عقد الإجارة بوعد بالبيع، أو مد مدة الإجارة، أو انتهاء الإجارة ورد العين المستأجرة إلى الماللك في نهاية مدة الإجارة.

وذلك بـأن بصـاغ العقد على أنهه عقد إجـارة مـع إعطـاء المالك الخيـار

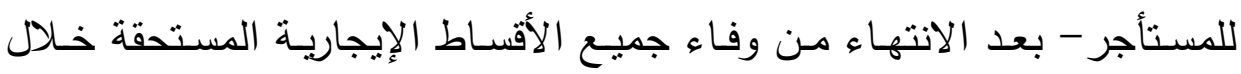
المدة- في واحد من الأمور الثنلاثة:

1- شراء العين المأجورة بسعر السوق عند انتهاء مدة الإجارة، أو بثن محدد عند بداية العقد.

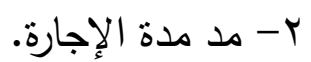

r- إنهاء عقد الإجارة ورد العين المأجورة إلى صاحبها(§؟). الصورة السادسة: الإجارة التمويلية.

وهذه الصورة هي تطور للإجارة المنتهية بالتمليك وتسمى (عقد الليزنج) أو

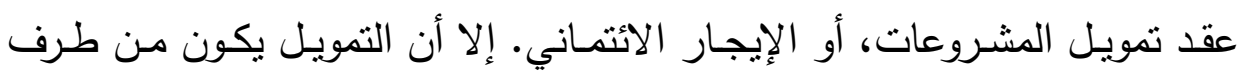

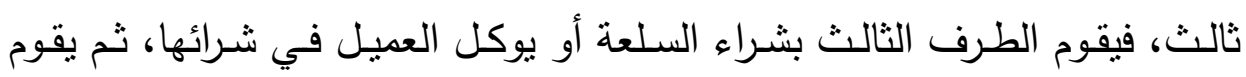

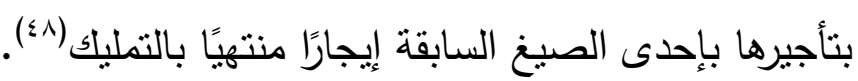

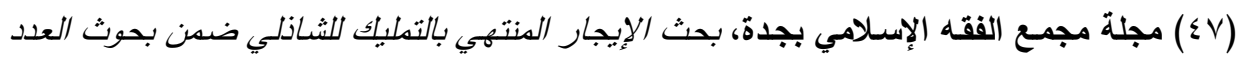

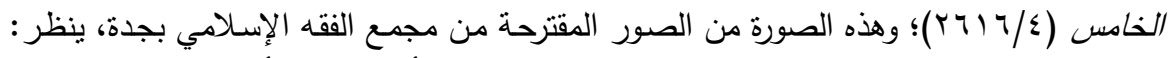

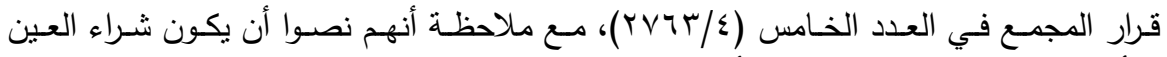

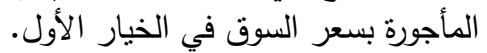

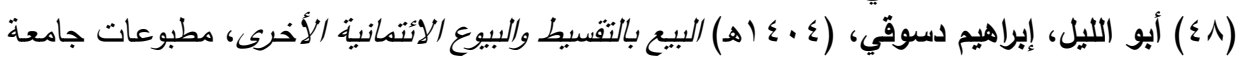

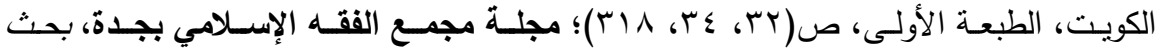

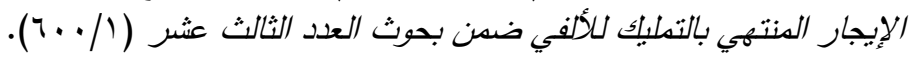


الصورة السابعة: الإجارة المنتهية بالتمليك بالبيع التدريجي للعين المؤجرة. وذلك بأن يتقق المصرف (المؤجر) مع العميل بأن يقوم العميل بشراء نسبة

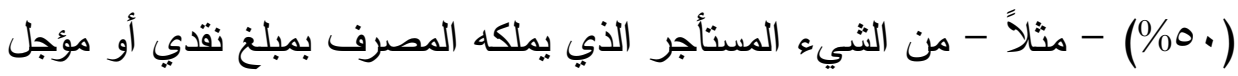
عن طريق المرابحة، ثم يؤجر المصرف ما يملكه للعميل (المستأجر) مع بيع تدريجي لحصة المصرف إلى أن ينتهي العقد بتمليك العميل كامل العين المستأجرة(9 ؛). أي أنه - في كل مدة - يدفع المستأجر أجرة العين ناقصًا منها الأسهم التي

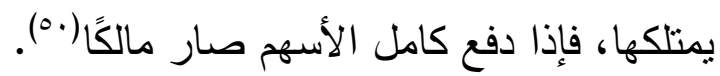

\section{الألفاظ التي تطلق على الإجارة المنتهية بالتمليك [1] الإجارة المنتهية بالتمليك:}

يطلـق على هذه المعاملـة الإجـارة المنتهيـة بالتمليـك، أو الإيجـار المنتهي بالتمليك، أو التأجير المنتهي بالتمليك، أو الإجارة التمليكية. وهي عبارات بمعنى واحد تطلق على الإجارة المنتهية بالتمليك، وهذا الإطلاق هو أثنهر الألفاظ التي تطلق على هذه المعاملة|(0). [ץ] الإيجار الساتر للبيع: يطلق على هذه المعاملة الإيجار الساتر للبيع؛ لأن حقيقته في بداية ظهوره التحايل، بجعل هذا العقد إيجارًا ليخفى صورته الحقيقية وهي البيع.

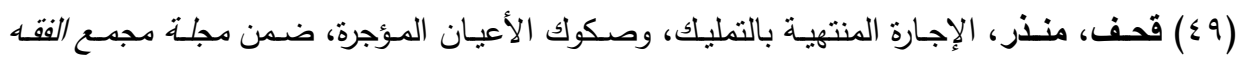

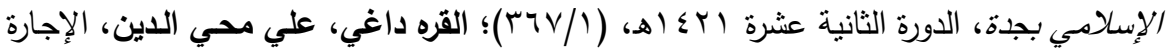

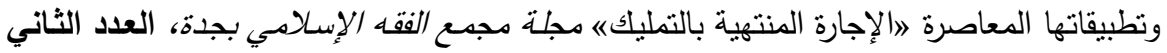

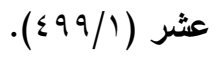

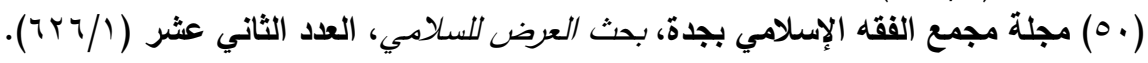

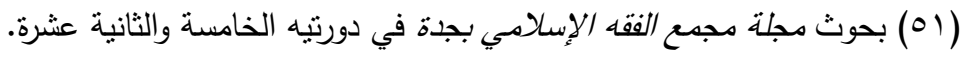


كما يسمى: البيع الإيجاري، أو الإيجار البيعي، أو الإيجار الذي ينقلب بيعًا(هما.

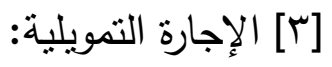

يطلق على هذه المعاملة الإجارة التموبلية، وذلك بأن يدخل في هذه المعاملة طـرف ثالث بـين طرفي العقد الأصـليين؛ ليقوم بتمويـل العقد، وتسـىى: الإجـارة

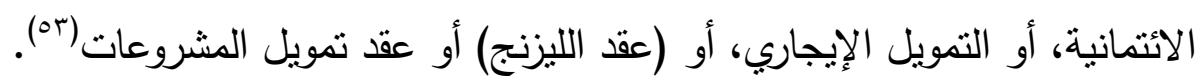

$$
\text { [§] الإجارة مع الوعد بالتمليك: }
$$

وهي من الألفاظ التي أطلقت على صورة منطورة لهذه المعاملة، وتم اقتراحها مـن قبـل الهيئات الثـرعية والمجامع الفقهيـة؛ لتكـون بـديلاً عن الإجـارة المنتهيـة بالتمليك، بحيث تكون بعقدين مستقلين، الأول إجارة، والثاني بيع أو هبة بناء على الإنى

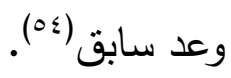

\section{[0] الإجارة المنتهية بالتخيير : [0}

يطلق هذا اللفظ على إحدى صور الإجارة المنتهية بالتمليك، وهي التي يكون

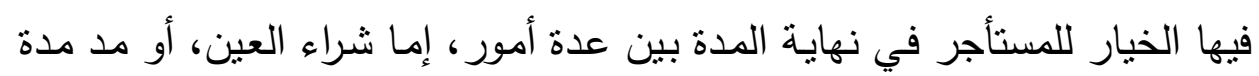
الإجارة، أو رد العين (00).

(ro) أبو الليل، إبراهيم دسوقي، (ع +ـ ا (ه) البيع بالتقسيط والبيوع الائتحانية الأخرى، مطبوعات جامعة

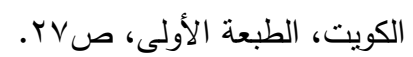

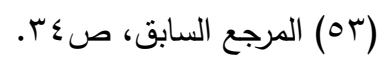

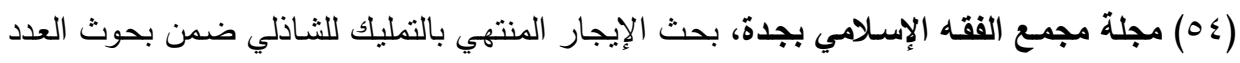

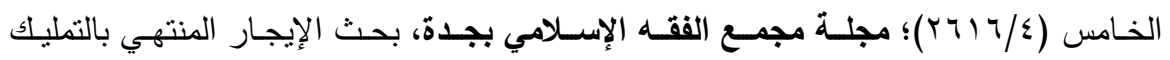

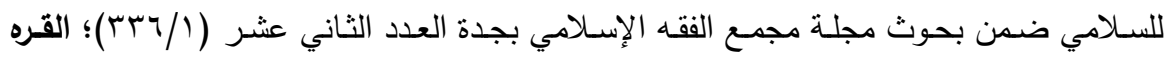

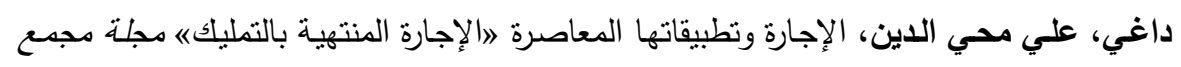

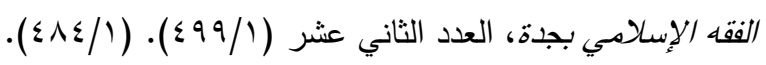

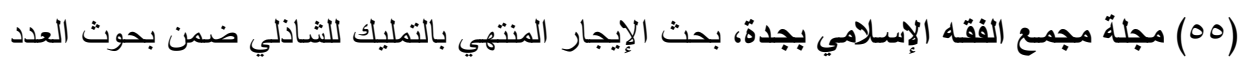

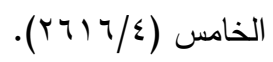


[†] الإجارة المنتهية بالبيع التدريجي للعين المستأجرة: يطلق هذا اللفظ على إحدى صور الإجارة المنتهية بالتمليك كما تقدم عند

بيان الصور (10).

$$
\text { [V] }
$$

يطلق بعضهم على الإجارة المنتهية بالتمليك الإجارة المالية من باب إطلاق الكل على البعض، فالإجارة المنتهية بالتمليك من فصيلة الإجارة المالية، والإجارة الماليـة هي اصطلاح اقتصـادي معاصـر لعقد الإجـارة تقابـل الإجـارة النشـيلية،

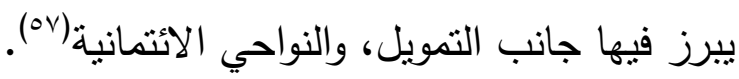
1- الإجارة المبتدئة بالتمليك: وهـذا اللفظ يطلق على صـورة مقترحسة لتكـون بـديلاً عـن الإجـارة المنتهيـة بالتمليـك، ولذلك لـم أذكرهـا ضـمن الصـور ، وتشـمى التمليك الحـال مـع اسـتثناء المنـافع، وتكون بييع العين إلى المستقفيد مـن التمويـل مـع استثناء منافعها لمدة الإجارة بثن يدفع عند العقد، ثم تباع المنافع المستثناة بعقد إجارة لمشتري العين نفسـ، فتكون الدفعـة الأولى لقاء ثـن العين، وتكون الدفعات الدوريـة التالية لقاء لاء

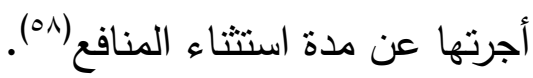

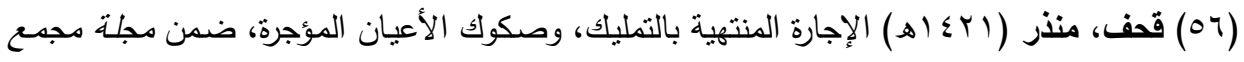

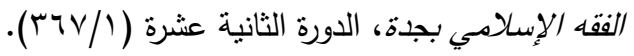

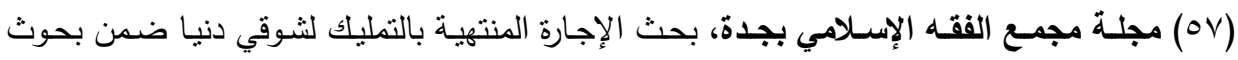

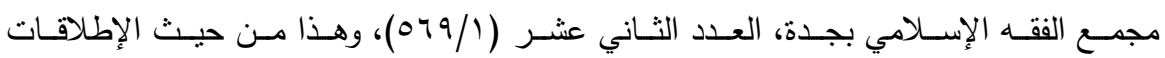

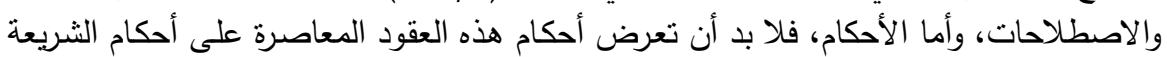

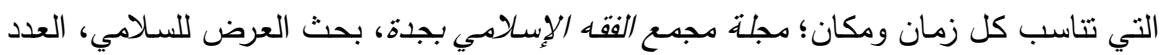

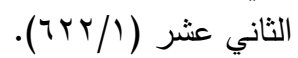

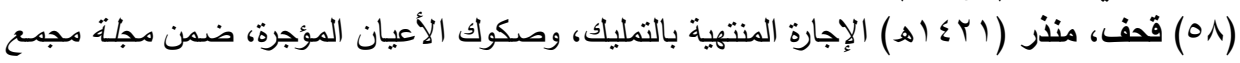

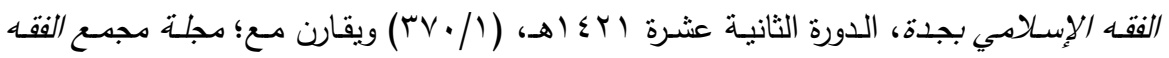

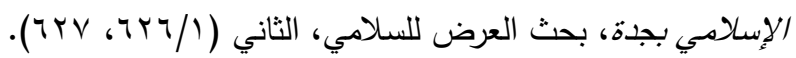


المسأنة الثانية: حكم الإجارة المنتهية بالتمليك

تعتبـر الإجـارة المنتهيـة بالتمليك فـي صـورها المشـهورة مـن العقود الماليـة المركبة، وفيما يأتي بيان حكمها، وذللك وفق الصور الآتية:

\section{حكم الصورة الأولى وهي: إجارة تتتهي بالتمليك دون دفع ثمن سوى الأقساط الإيجارية}

وهذه الصورة فيها جمع بين الإجارة والبيع المعلق على سداد كامل الثمن،

والعقد فيها متردد بينهما غير مستقر على واحد منهما.

وهذا التركيب في هذه الصورة له أثز في حكم هذه المعاملة؛ حيث إنه يؤدي

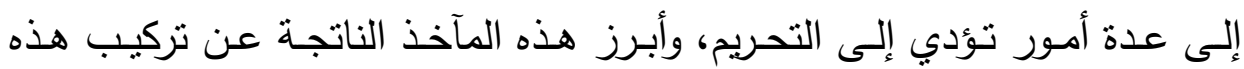

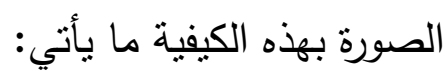

1- أن العقد غير مستقر على واحد من العقدين المكونين لهذه المعاملـة، وذلك أنه متردد بين أن بكمل الأقساط فيكون بيعًا (9)، وأن لا يكمل فيكون ما دفعه أهن أجرة مقابل عقد الإجارة.

ץ- أن في هذه المعاملة جهالة للثمن والأجرة، بسبب التردد بين العقدين(·r). ب- أن في هذه المعاملة غررًا، وأكلاً لأموال الناس بالباطل؛ لأن المستأجر

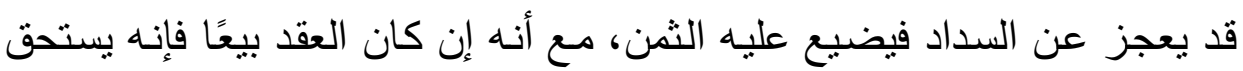

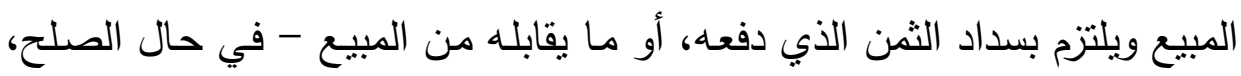
وفسخ العقد-، كما أن المشتري يستحق الثمن عند فسخ المبيع بعيب أو نحوه.

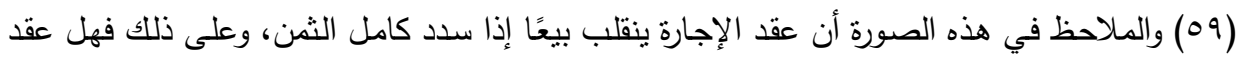

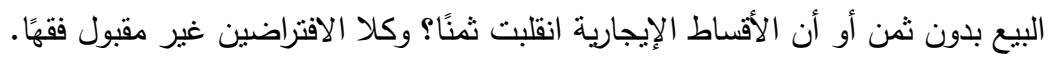

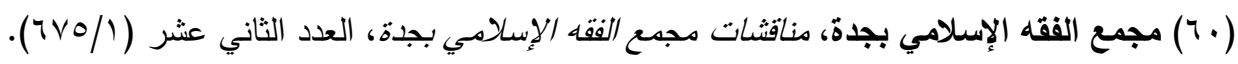


وإن كان ما دفعه أجرة لمنفعة العين في عقد الإجارة فإنه دفع أكثر من أجرة المثل؛ طمعًا في الحصول على رقبة العين المعقود عليها، فيكون المشتري خاسرًا للثن والمثمن، ويكون البائع قد حصل على الثمن والمثن، وفي هذا ظلم لأحد

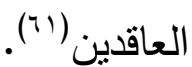

ووجه الغرر في هذه المعاملة هو دخوله في عقد على سلعة ربما تحصل لله

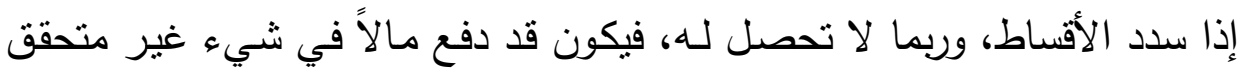
الوقوع، وإنما هو منردد بين الحصول وعدمه.

ـ- أن العقدين عقد الإجارة والبيع منواردان على عين واحدة، وبالنظر للواقع العملي لهذه المعاملة يتبين وجود التتافي بين العقدين في بعض الآثار والأحكام، كالضمان، والصيانة، وغيرها من الأحكام، وذللك أن الضمان في عقد الإجارة يكون لهان

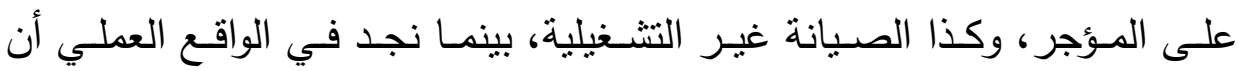
الضمان، والصيانة، يكونان على المستأجر ، مما بدل على أن حقيقة العقد ليست إجارة، وإنما بيعُ، أو أنها إجارة لكن اشتنرط فيها ما ينافي أحكامها. ويتبين كذللك أنه لا يصسح توارد العقدين على محل واحد في وقت واحد مـع

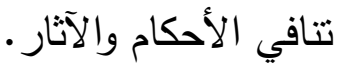

وبهذا صـدرت الفتاوى والقرارات بمنـع هذه المعاملـة، مثل قرار هيئة كبـار

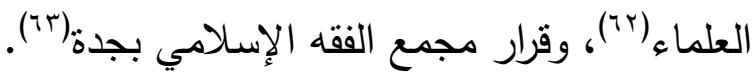
وبهذا يتنين أن التركيب في هذه الصورة أدى إلى التحريم، للأسباب السابقة.

(17) مجلة مجمع الفقه الإسلامي بجدة، بحث الإيجار الهنتهي بالتمليك لابن بيه ضدن بحوث مجلة

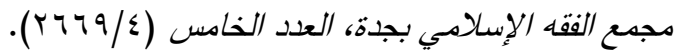

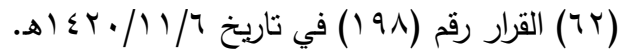

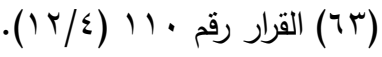


هذا وقد اقترح تصحيح لهذه الصورة، كما في توصيات الندوة الفقهية الأولى الكى

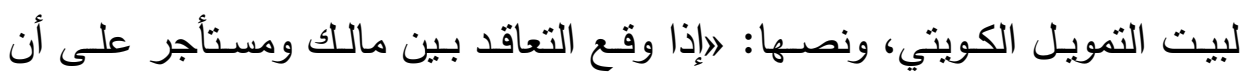

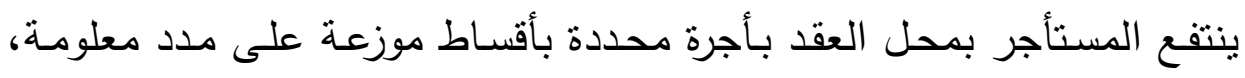
على أن ينتهي هذا العقد بملك المستأجر للدحل، فإن هذا العقد يصـح إذا بأها روعي فيه ما بأني: - ناني

(أ) ضبط مدة الإجارة، وتطبيق أحكامها طيلة تلك الددة. (ب) تحديد مبلغ كل قسط من أقساط الأجرة.

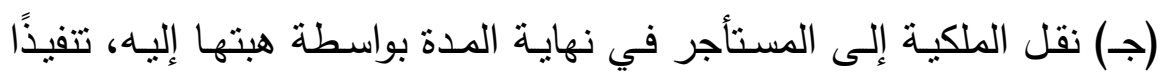

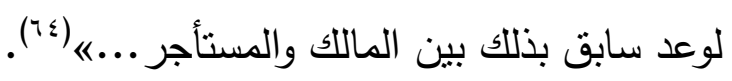
وجاء في التأجير المنتهي بالتمليك(70): (افبناءً على ذلك يصح تخريج عقد

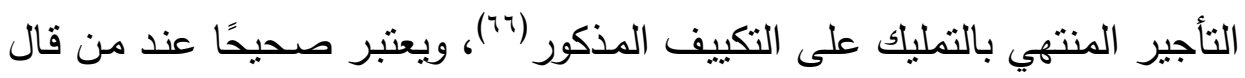
بجواز هذه المسائل جميعها، إلا أنه يراعى في تطبيق ذلك أمور : 1- يجب أن يترتب على عقد الإجارة جميع آثاره خلال المدة المتفق عليها،

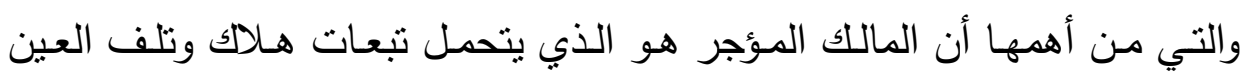

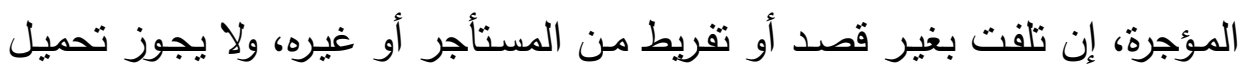
ذللك على المستأجر ؛ لأن هذا هو مقتضى عقد الإجارة.

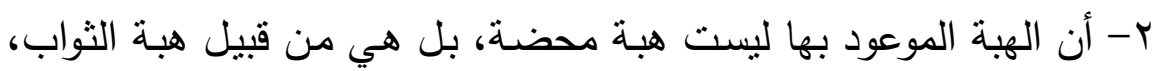

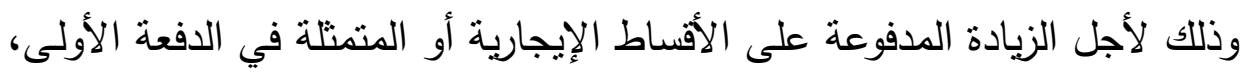

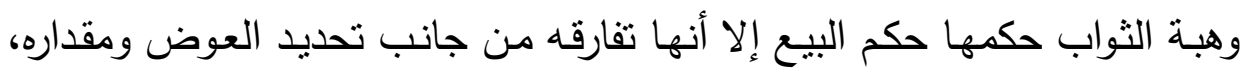

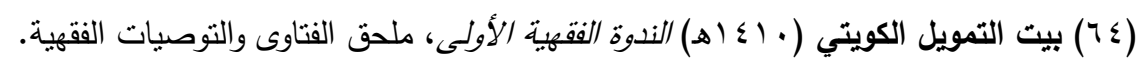

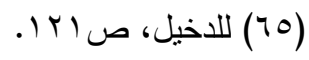
(77) عقد إجارة ينتهي بهبة العين المؤجرة إلى المستأجر . للإل 
فقي هبـة الثواب العـوض مسكوت عنـه، وعن مقداره. وتحديده راجهع إلى قيهـة الموهوب أو إلى ما يرضى به الواهب، فإذا طرأ ما يفسخ العقد فلمن فات غرضـه بالفسخ الرجوع على الآخر بقدر ما فاته، فلو فسخ العقد بآفة سماوية أو من جهة

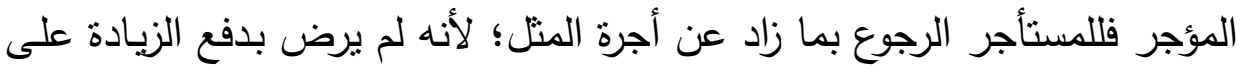

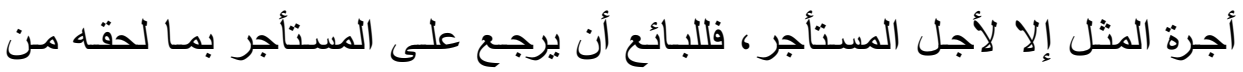
ضرر؛ بناء على ما شرطاه من شروط جزائيةه.

وخلاصة رأي المصححين لهذه الصورة أنها تصح إذا روعيت ضوابط أبرزها: 1- أن يكون العقد عقد إجارة تترتب عليه آثناره وأحكامه طيلة المدة. r- في حالة فسخ العقد يرجع المستأجر على المؤجر بما زاد عن أجرة المثل. إلا أنـهـ يؤخذ في الاعتبـار ضـرورة وجـود جهـة رقابيـة لتطبيـق ذلك بشكل صحيح، وإلا فإن الواقع يدل على أن تطبيق هذه الصورة بما فيها من مآخذ هو إلى الأكثز شيوعًا، وعلى ذللك فتمنع سدًا للذربعة.

وخلاصة القول في بيان أثز التركيب، هو أنه بالتأمل في الصورة المصححة يتبين أنها لا تكون صحيحة إلا بتطبيق أحكام الإجارة طيلة المدة، أي أن العقدين لا يتواردان في وقت واحد، بينما الصورة محل البحث لا يوجد فيها هذا الانفصال،

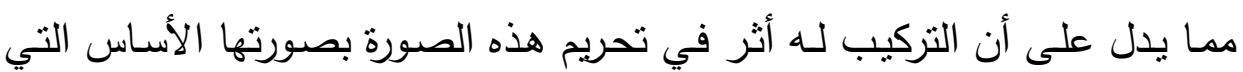
هي محل البحث؛ للمآخذ السابقة التي أثرت فيها، وأدت إلى التحريم.

حكم الصورة الثانية وهي: اقتران الإجارة ببيع الثيء المؤجر بثمن رمزي هذه الصورة عقد دركب فيها جمع بين عقد الإجارة وعقد البيع المعلق على

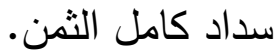
وهذا التركيب يؤدي إلى الغبن، وأكل أموال الناس بالباطل؛ وذلك لأنه في

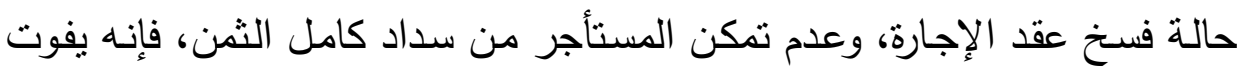


عليه تملك العين التي كان يرغب في تملكها، وتفوت عليه الأقساط الكبيرة التي هي أكثر من أجرة المثل، والتي دفعها أملاً في تملك العين. وأثنار بعض الباحثين إلى مأخذ آخر على هذه الصورة مفاده: أن اقتران عقد الإجارة - مع تحديد الأجرة المرتفعة كثيرًا عن أجرة المثل خلال المدة التي اشترط استمرار الإجارة فيها بهذه الأجرة- بعقد البيع في نهاية هذه المدة، وبعد سداد هذه

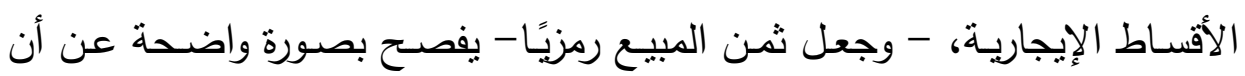
المقصود هو عقد بيع من أول الأمر، وليس عقد إجارة ثم عقد بيع، وأن كل ما

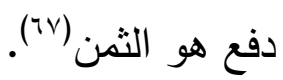

كما أن جعل الثمن رمزيًا يبطل العقد؛ لجهالة الثمن، لما تقدم من أن الثمن الحقيقي لم يسمياه(r) - (r).

حكم الصورة الثالثة، وهي: اقتران الإجارة ببيع الثيء المؤجر بثمن حقيقي هذه الصورة هي عقد مركب من عقدين على عين واحدة(99). والعقدان هما عقد إجارة، وعقد بيع معلق على شرط هو سداد كامل الثمن. وهذا التركيب يؤدي إلى جهالة الثمن والمثمن.

(V) مجلة مجمع الفقه الإسـلامي بجدة، بحث الإيجار المنتهي بالتمليك للشاذلي ضمن بحوث مجلة

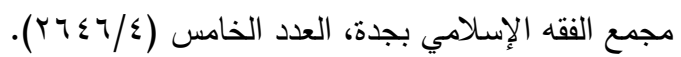

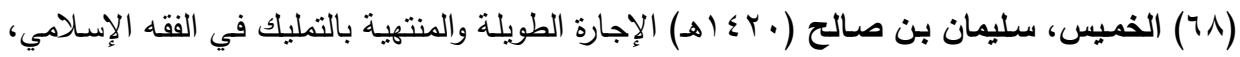

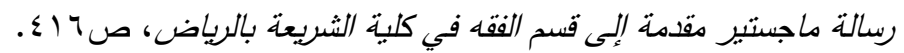

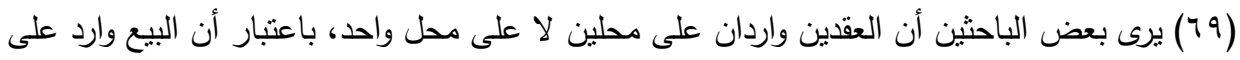
الرقبة، والإجارة واردة على المنفعة.

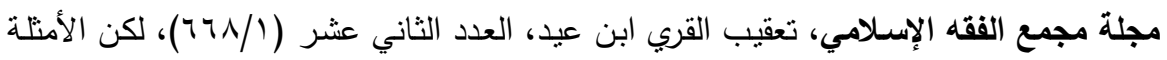

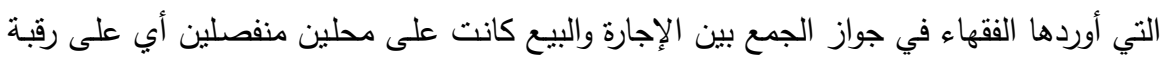
عين ومنفعة عين أخرى. 
أما جهالة الثمن فتكون حينما يكون الاتفاق على ثمن حقيقي هو سعر السوق في نهاية المدة؛ وذلك لأن سعر السوق في نهاية المدة أمر مجهول، علمًا بأن هذه المسألة وهي تعليق البيع على سعر السوق لاحقًا تختلف عن مسألة البيع بسعر لهان السـوق عنـــ إنشـاء العقد، والتـي أجازهـا بعض الفقهاء، ويمكن أن تصـاغ هـذهـ الصورة بالكيفية السابقة وهي شرط البيع بسعر السوق مع جعل الخيار للمشتري أو

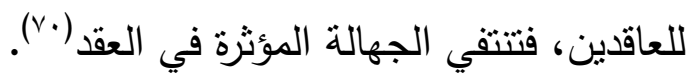

وأمـا جهالة المثن فتكون حينما يكون الاتفاق على ثمن حقيقي عند العقد

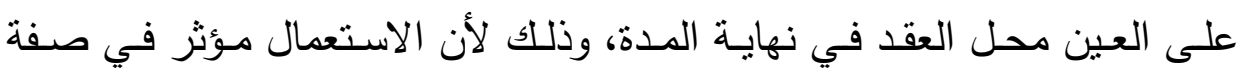
المبيعُ، وهذا مؤدٍ لجهالة المبيعع (VI)، والعين يختلف سـعرها بـاختلاف استعمالها وتشغيلها، وقد تتلف بدون تعد ولا تقريط بحيث لا تساوي شينًا. فتبـين ممـا تقدم أن التركيب في هذه الصسورة يـؤدي إلى جهالـة في الثمن والمثنن، فأدى إلى التحريم.

وأما إذا قيل إن العقدين منفصـان بحيث يكون العقد عقد إجارة تترتب عليه أحكامه، ثم يتبعه تمليك حسبما يتفقان عليه في حينه، فإن هذه صورة جديدة ليس فيها تركيب، وإنما هي إجارة ثم بيع مستقل.

حكم الصورة الرابعة، وهي: اقتران الإجارة بوعد بالبيع هذه من الصور الجائزة، والتي نص قرار المجمع الدولي على جوازها. حكم الصورة الخامسة، وهي: الإجارة المنتهية بالتخيير هذه الصـورة فيها تركيب في حالـة مـا إذا كـان الخيـار للمستأجر مـع إلزام المؤجر بذلك بسعر السوق.

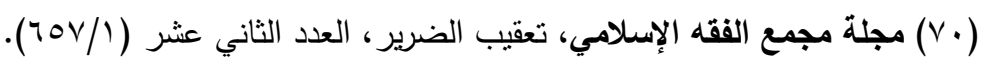

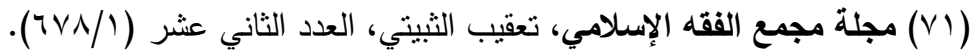


وهذه الصورة محل تأمل، من حيث مدى تأثير هذا التركيب على حكم هذه الصورة؛ وذلك لأن سعر السوق في المستقبل فيه جهالة بالنسبة للمؤجر ، لكن إذا هـا هذان كان الخيار للمستأجر فالذي يبدو أن ذلك جائز ، وذلك أن لزوم العقد لا يكون إلا

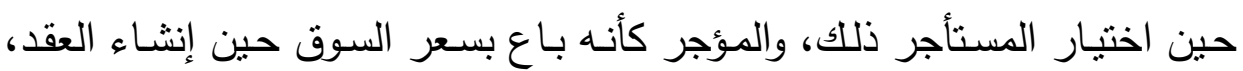
فتكون الجهالة يسيرة حينئذٍ، ولا نؤُثز على صحة وأجر العقد. والله أعلم.

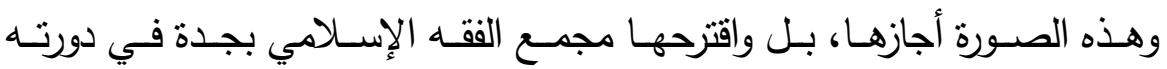

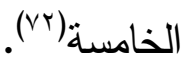

\section{حكم الصورة السادسة، وهي: الإجارة التمويلية}

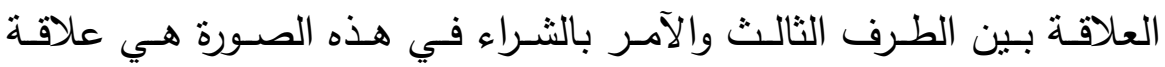
المرابحة المركبـة، ويتوقف الحكم عليها على إجراء عقد المرابحة للآمـر بالشـراء وفق الضوابط الشرعية.

\section{حكم الصورة السابعة، وهي: الإجارة المنتهية بالتمليك بالبيع التدريجي} حقيقة هذه الصورة هي المشاركة المتتاقصة، وينوقف الحكم عليها على إجراء عقد المشاركة المتناقصة وفق الضوابط الثرعية. يتبين مما سبق تعدد صور المسألة وتشعبها، ومدى تأثنر التركيب(Vr) في كل صورة.

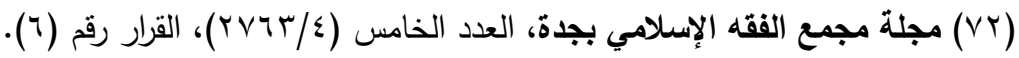
(VT)

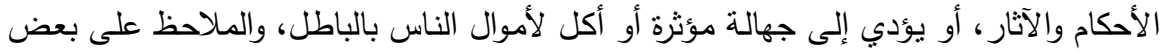

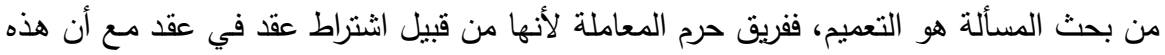

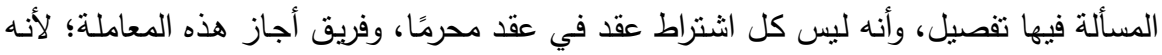

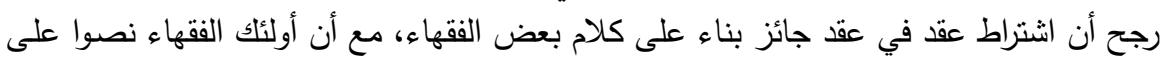

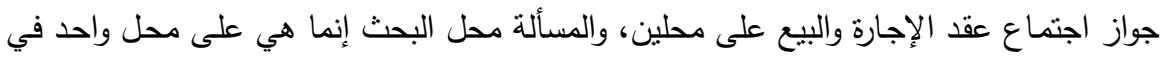

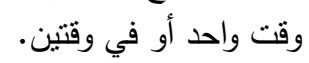
ينظر : - على سبيل المثال - الإجارة المنتهية بالتمليك للحافي، صـ 1 أ. 
المسألة الثالثة: حكم إصدار صكولك الإجارة المنتهية بالتمليك

تقدم الكلام على حكم الإجارة المنتهية بالتمليك، والحديث عنها عن الصور الجائزة وفق الضوابط التي وردت في قرار المجمع الفقهي الدولي.

وبناء على ذلك فإنه يجوز من حيث الأصل إصدار صكوك إجارة منتهية

بالتمليك بناء على عقد الإجارة، وهي إجارة منافع أعيان، وتراعى الضوابط

الشرعية لعقد الإجارة وصكوك الإجارة عند التطبيق العملي.

وفيما يأتي أورد مثالين يمكن تصورهما في هذه المعاملة:

المثال الأول: شركة (س) لتأجير السيارات تأجيرًا المنتهية بالتمليك.

- تقوم بإنشاء محفظة لشراء مجموعة من السيارات بغرض التأجير المنتهي بالتمليك.

- تقوم بتأجير السيارات تأجيرًا منتهيًا بالتمليك لصالح حملة الصكوك. - يستحق حملة الصكوك الأجرة الدورية. - بعد سداد كامل الأقساط ينتهي الصك بعد استيفاء حملة الصكوك جميع القيمة مع الربح.

المثال الثاني: شركة (س) لتأجير الطائرات تأجيرا منتهيا بالتمليك. تقوم شركة (س) بشراء طائرات من شركة (بوينج) ومن ثم تقسيم المحفظة إلى صكوك.

- تقوم شركة (س) بتأجير الخطوط الجوبة هذه الطائرات تأجيرًا منتهياً بالتمليك. - بعد سداد كامل الأقساط يتم تملك الخطوط الجوية للطائرات وبذلك بكون حملة الصكوك قد تسلموا جميع القيمة مع الربح. 
المسألة الرابعة: حكم تداول صكوك الإجارة المنتهية بالتمليك

يجوز تداول هذه الصكوك ما دامت تمتل حصة شائعة في ملكية موجودات الأعيان وفق المعايير والضوابط الثرعية.

المبحث الثالث: صكوك إجارة العين لمن باعها إجارة منتهية بالتمليك المسألة الأولى: تعريف إجارة العين لمن باعها إجارة منتهية بالتمليك صورة المسألة: أن يقوم المشتري بإجارة العين التي اشتراها لمن باعها منه

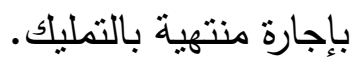
والإجارة إما أن تكون إجارة تشغيلية أو منتهية بالتمليك لكن محل المسألة المطلوبة إجارة منتهية بالتمليك. المسألة الثانية: حكم إجارة العين لمن باعها إجارة منتهية بالتمليك

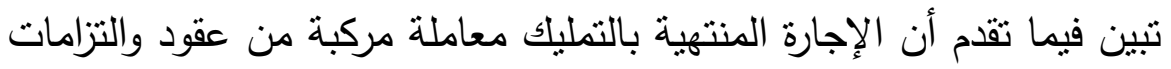
متتابعة مترابطة، تهدف إلى تحقيق غرض تمويلي تبدأ بتأجير العين، وتتنهي

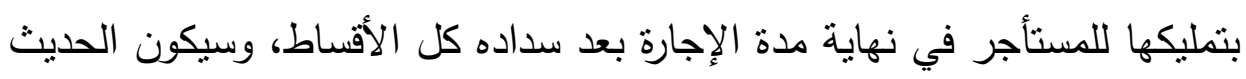

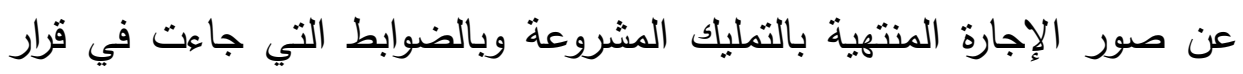

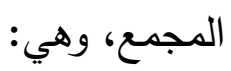

ا. .وجود عقدين منفصلين، يستقل كل منها عن الآخر زمانًا، بحيث يكون إبرام عقد الهية أو الوعد بهما بعد عقد الإجارة.

r. أن تكون الإجارة حقيقة فعلية، وليست ساترة للبيع.

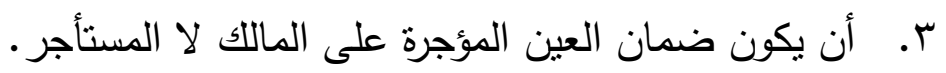

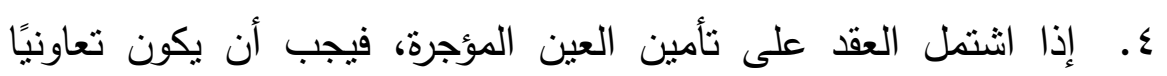

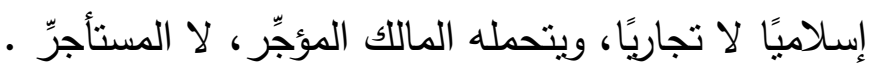


0. يجب أن تطبق على عقد الإجارة المنتهية بالتمليك أحكام الإجارة طوال

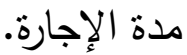

7. تكون نفقات الصيانة غير النشغيلية على المؤجر لا على المستأجر طوال مدة الإجارة.

أما مسألة إجارة العين لمن باعها إجارة منتهية بالتمليك فقد اختلف المعاصرون فيها على قولين:

القول الأول: عدم جواز هذه المعاملة وهذا قول أكثر المعاصرين منهم الأستاذ الاكتور الصديق الضرير (؟ع).

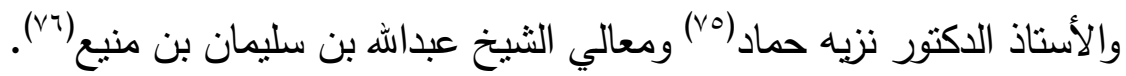
القول الثاني: جواز هذه المعاملة وهذا قول بعض المعاصرين ومنهم الدكتور

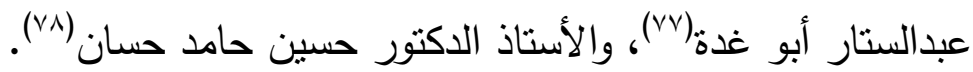
أدلة القول الأول: - ألقا الاليل الأول: أن صكوك الإجارة في هذه المعاملة بهذه الصيغة من العينة المحرمة فهي عكس العبنة. وذلك أن صكوك الإجارة بالوصف السابق عبارة عن منظومة عقدية منرابطة تتألف من عقود ووعود منتابعة على وجه لا يقبل التجزئة صيخت لتحقيق هدف

(V乏)

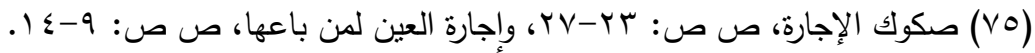

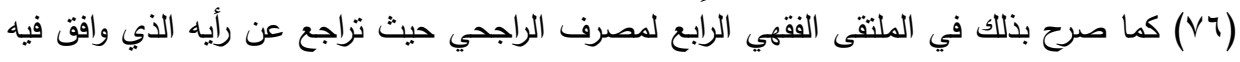
على إجازة منتج صكوك بكان فكومة البحرين. ينظر تعقيبه في ملتقى الراجحي. (VV) ينظر تعقيبه في ملتقى الراجحي. (V) 
تمويلي محدد، يتلخص في أن طالب التمويل - المقترض - قد باع عقارًا يملكه إلى الممول - المقرض - (حملة الصكوك) بثمن معجل ثم استعادته بتأجير منته

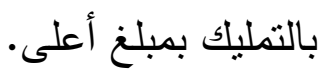

فيكون مصدر الصكوك قد باع عينًا بثمن حال ثم استعاد ملكيتها ممن باعها منه بثمن مؤجل مقسط يزبد عن الثمن الحال(va).

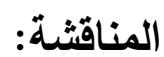

نوفش بما يأتي أولاً: أن العينة المحرمة لا تتحقق إلا بشروط ومنها: ألا يتغيّر

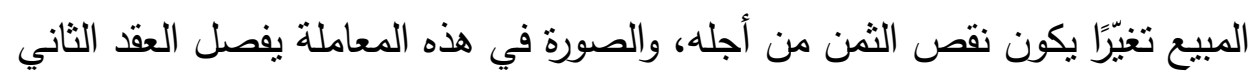
فيها عن العقد الأول مدة طوبلة، هي كفيلة بحوالة الأسواق وتغيّر حال المبيع، ثم إنه قد ثم الفصل بين البيعة الأولى والثانية بعقد أجنبي طويل الأمد، وعليه فإنه بنتفي وصف العينة عن صكوك الإجارة في هذه المعاملة بهذا الاعتبار (•^.).

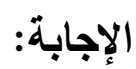

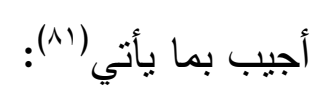

ا . أن العينة لم تحرم لذاتها وإنما لكونها ذربعة وحيلة على الربا، وعليه فإنه وإن قيل بأن هذه الثروط قد انتقت فإن صكوك الإجارة هنا صيغة ظاهرة كونها ذربعة إلى الربا.

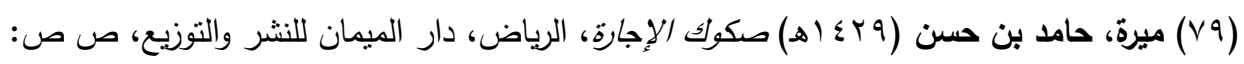

$$
\text { . } \varepsilon \cdot V-\varepsilon \cdot \tau
$$

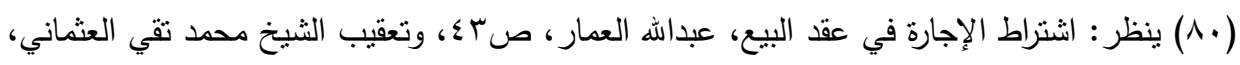

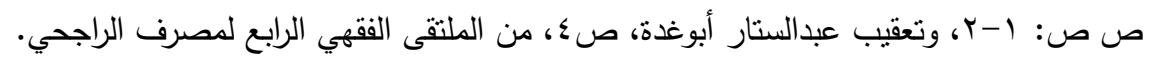

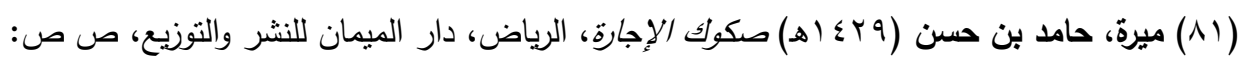


r. . أن ما ذكر من مضي مدة طويلة بين العقدين هو أمرٌ غير مؤثز ، ولا ينفي الحيلة الربوية في صكوك الإجارة، وذلك لأن العوض الثاني محدد مسبقًا، والزيادة (الأجرة) محددة سلفًا مع تعهد وضمان كامل من المصدر باستمرار الإجارة، ثم الثراء بالحالة التي تكون عليها، وبالثمن المعلوم المحدد سلفًا، وعليه فلو كان شراء العين بعد عشر سنوات مثنلاً بسعر السوق الحقيقي - لكان مقبولاً ما ذكر من وجود مدة كافية لحوالة الأسواق.

ثانيًا: أن العقود الفاسدة إذا أمكن تصحيحها على وجه فهو الأولى. وما ذكر من كون صكوك الإجارة من قبيل بيع العينة له وجاهته، ولكن يمكن تصحيح العقد ونفي العينة بإدخال طرف ثالث، ومثاله: أن بييع (البائع) إلى وسيط مالي (بنك) العين، وعندما يملكها وتدخل في ضمانه يقوم بتصكيكها وبيعها للمستثرين ثم يقومون هم بإجارتها على (البائع) تأجيرًا منتهيًا بالتمليك.

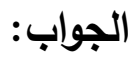
أجيب: بأن العينة إنما حرمت لما تؤول إليه من ربا المحرم، فلا ينقلب الحرام حلالًا بإدخال طرف ثالث (r^^).

يقول ابن قيم الجوزية ((وللعينة صورة خامسة، وهي أقبح صورها وأثدها تحريمًا، وهي أنَّ المترابيين يتواطآن على الربا ثم يعمدان إلى رجل عنده مناع فيثتريه من المحتاج ثم يبيعه للمربي بثمن حالٍ ويقبضه، ومن ثم يبيعه إياه للمربي ثمن مؤجل وهو ما اتفقا عليه، ثم يعيد المتاع إلى ربه ويعطيه شينًا، وهذه تسمى الثلاثية، لأنها بين ثلاثة وإذا كانت السلعة بينهما خاصة فهي الثنائية، وفي

(r^) ينظر : تعقيب عجيل النشمي في الملتقى الفقهي الرابع لمصرف الراجحي، ص \؛ وصكوك الإجارة

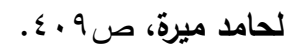


الثلاثية أدخلا بينهما محلاً يزعمان أنه يحلل ما حرم الله من الربا، وهو كملل النكاح، فهذا محلل الربا، وذلك محلل الفروج، والله لا تخفى عليه خافية، بل بعلم خائنة الأعين وما تخفي الصدور )( (r^).

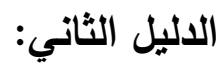
تعد صكوك الإجارة في هذه المعاملة صورة من بيع الوفاء الذي نص جمهور

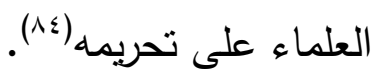
وبيع الوفاء: أن يتواطأ اثثان على أن يقرض أحدهما الآخر مبلغًا من المال،

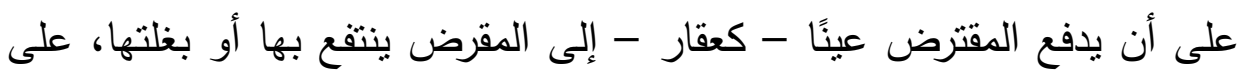
أنه منى ما رد المال رد العين. فيرجع إليه القرض وزيادة منفعة العقار .

وصكوك الإجارة هنا بنطبق علبها هذا القصور، لأنَّ مصدر الصكوك في

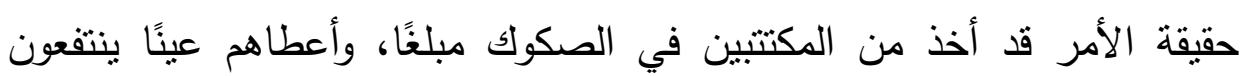
بغلتها، حتى يرد المبلغ في نهاية المدة.

(المناقشة:

نوقش: بأنه من المحتمل النكول عن الوعد، وعدم الإبرام للبيع بمعارضة المستأجر أو المؤجر، فيتبين أن عودة الأعيان المؤجرة إلى الملك السابق ليست حتمية، وأنها إن عادت تعود من خلال عقد البيع الذي لا بد منه مع وجود التعهد، وبهذا يزول الاشتباه بأن إجارة العين لمن باعها إجارة منتهية بالتمليك من قبيل بيع

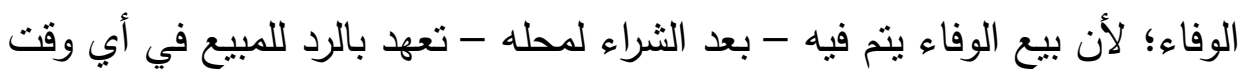


يعيد فيه البائع الثمن للمشتري، وهذا الرد ملزم ولا يحتاج إلى عقد بيع جديد بين المالك الحالي والمالك السابق بل يثبت الحق للماللك السابق بمجرد رد الثن (القرض) ولا يملك المشتري بالوفاء البيع للغير • في حين أن المؤجر في التأجير المنتهي بالتمليك يملك البيع للغير وتتقل الملكية محملة بالوعد بالتمليك كما ينتقل حق أي مستأجر في حالة بيع المؤجر الأصل المؤجر إجارة تشغيلية(^هـ. الجواب:

\section{يمكن أن يجاب من وجهين:}

ا. أنه لا يسلم بوجود هذا الفرق لأن المعاملة حسب تطبيقها في الواقع معاملة مركبة من عقود والتزامات مترابطة لا مجال لتخلف أي من الالتزامات فيها حسب الطريقة التي تجري بها. r. أنه وإن سلم وجود هذا الفرق فإن العبرة بالنتائج التي تؤدي إلى هذه المعاملة، فإنها تتشابه مع بيع الوفاء. الاليل الثالث: أن صكوك الإجارة في هذه المعاملة صيغة مركبة من جملة من العقود الصورية، مؤداها أنها حيلة على الربا. ويتضح ذلك من خلال ما يأتي: ا. أن هذه الصكوك ما هي إلا السندات الربوية مع تغيير الأسماء فالسند سمي صك إجارة، وعائد السند سمي أجرة، وما يمثله السند من قرض سمي ملكية عين مؤجرة، واسترداد قيمة السند عند إطفائه سمي بيع العين على المستأجر . r. ازدادت الصكوك على السندات بمجموعة من الأوراق التي يوقعها الطرفان في مجلس واحد، فهي دراهم بدارهم بينهما حربرة، ويكون إثمها أكبر لاقتران الربا بالحيلة. 
r. أنه ليس للمكتثين غرض صحيح في تملك العين المبيعة، خصوصًا مع جهالة العين المبيعة، في بعض التطبيقات.

ع. أنه وجد في بعض التطبيقات(ז^) بيع لمرافق حيوية، لا بتصور أن تنتازل فيها الدول حقيقة عن ملكية مرافقها السيادية، وتجعل التصرف فيها لغيرها من المواطنين والأجانب. مما بدل على أن العقد صوري وليس حقيقًا، الهدف منه

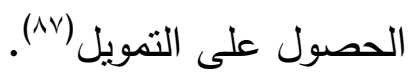
أدلة القول الثاني: جاءت أدلة القول الثاني مضمنة في المناقنشات لأدلة القول الأول.

الراجح:

يتبين من خلال الأدلة والمناقثنات أن الراجح والله أعلم هو القول الأول، وهو منع هذه الصورة، وعلى ذلك فلا يجوز تصكيكها أو تداولها.

\section{المراجع}

ابن فارس، أبو الحسن (T إ؛ (هـ) معجم مقابيس اللغنة، تحقيق: عبدالسـلام هارون، بيروت: دار الجيل، الطبعة التاسعة.

ابن منظور، محمد، لسان العرب، بيروت: دار صادر، الطعاد، الطبعة الأولى.

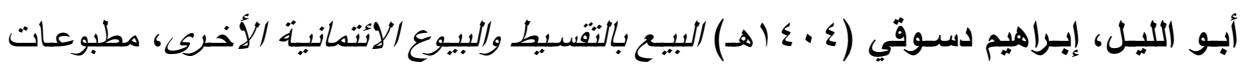
جامعة الكويت، الطبعة الأولى. الباجي، أبو الوليد سليمان بن خلف، الدنتقى شرح الدوطأ، بيروت: دار الكتاب الإسلامي.

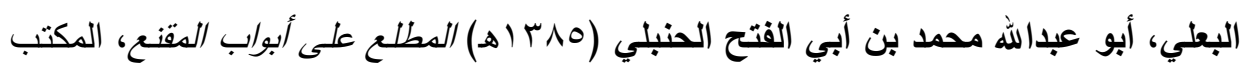

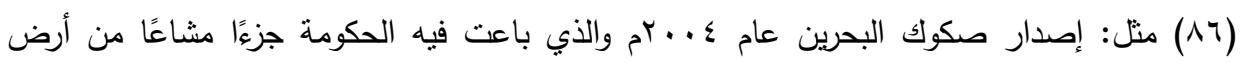
مطار البحرين الدولي. (Av) 
الإسلامي للطباعة والنشر ، دمشق، سوريا، بيروت، لبنان، الطبعة الأولى.

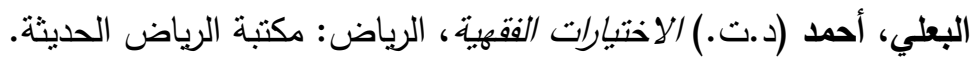

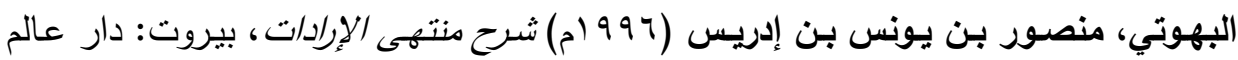
الكتب الطبعة الثانية. البهوتي، منصور بن يوسف بن إدريس (r • ـ اهـ)كشاف القناع عن منن الإقناع، تحقيق: طلال مصيلحي، بيروت: دار الفكر .

بيت التمويل الكويتي (• (1 اهـ) الندوة الفقهية الأولى، ملحق الفتاوى والتوصيات الفقهية.

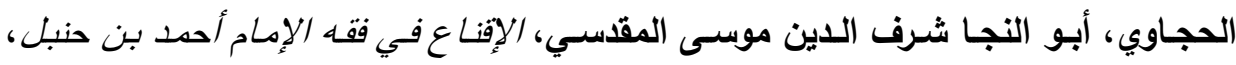

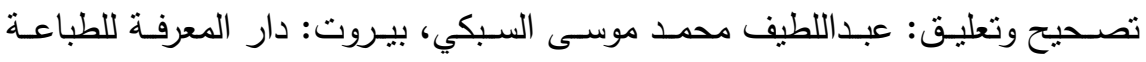
والنشر

حسـان، حسين حامــ (د.ت.) صكوك الاستثمار ، بحث غير منشسور مقدم لهيئة الدحاسبة والمرجعة للمؤسسات المالية الإسلامية بالبحرين.

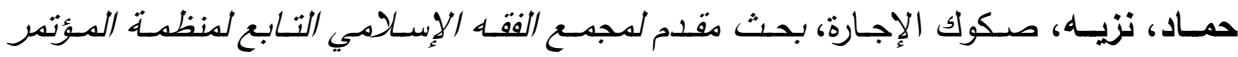

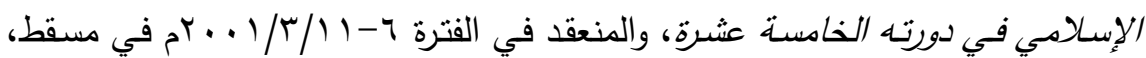
سلطنة عمان. الخميس، سليمان بن صالح (•r أ اهـ) الإجارة الطويلة والمنتعية بالتمليك في الفقه الإسلامي، رسالة ماجستبر مقدمة إلى قسم الفقه في كلبة الثريعة بالرياض.

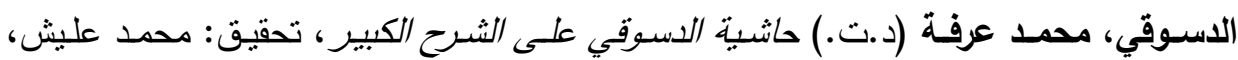

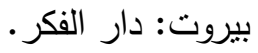
دنيا، شوقي أحمد ( إY اهـ) الإجارة المنتهية بالتمليك دراسة اقتصادية وفقهية، ضمن مجلة

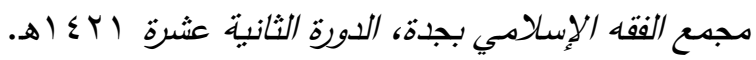

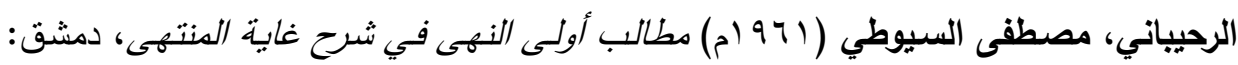

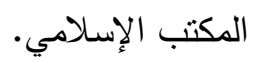
الزيلعي، فخر الدين الحنفي (با إ (هـ) تبيين الحقائق شرح كنز الدقائق، القاهرة: دار الكتب الإسلامية. السرخسي، شمس الدين (1 ـ ـ الهـ) المبسوط، بيروت: دار المعرفة. 
الثرييني، محمد الخطيب (د.ت.) مغني الدحتاج في شرح الدنهاج، بيروت: دار الفكر.

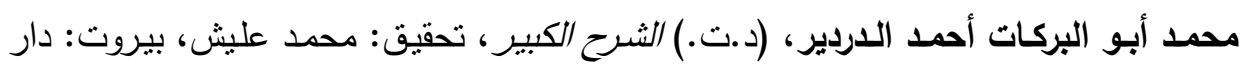
الفكر

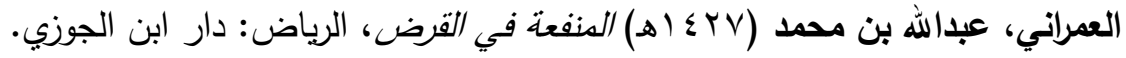

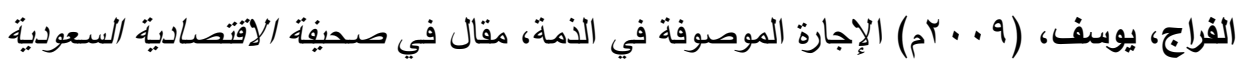

$$
\text { . } 9 / 1 . / 4 z
$$

الفيروزآبادي، مجد الدين محمد بن يعقوب (V) • أهـ) القاموس الدحبط، تحقيق: مكتب تحقيق التراث، بيروت: مؤسسة الرسالة، الطبعة الثانية.

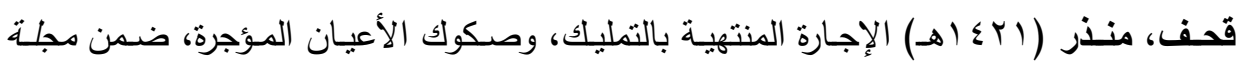
مجدع الفقه الإسلامي بجدة، الدورة الثانية عشرة. قحف، منذر (10 إهـ) سندات الإجاة والأعيان المؤجة، المعهد الإسـلامي للبحوث التدريب الإنة بالبنك الإسلامي للتتمية، الطبعة الأولى.

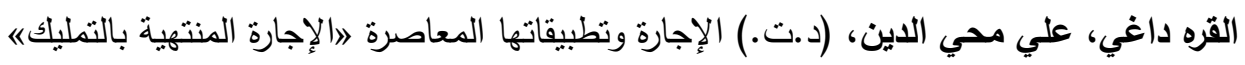

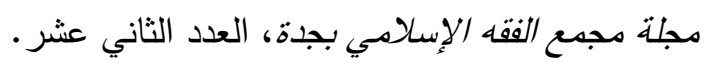

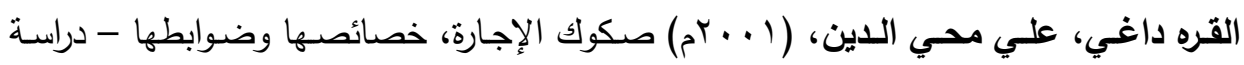

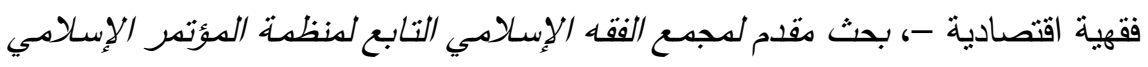

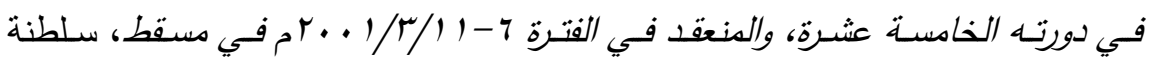
عمان. القليويي، شهاب الدين أحمد بن أحمد بن سـلامة (9 اءــانه) حاشية قليوبي وعمبرة، تحقيق:

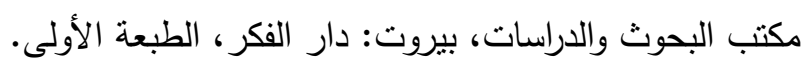

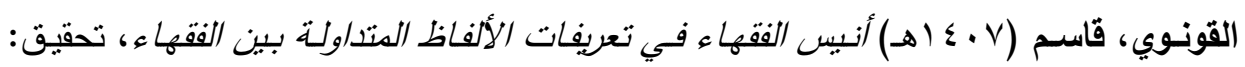
أحمد بن عبدالرزاق الكبيسي، جدة: دار الوفاء للنشر والتوزيع، الطبعة الثانية.

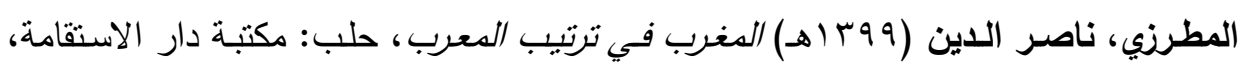
الطبعة الأولى. ميرة، حامد بن حسن (9 § ( هـ) صكوك الإجارة، الرياض: دار الميمان للنشر والتوزيع. 
النسـي، نجم الدين أبـو حفص عمر بن محمد (ج آـ (هـ) طلبة الطلبة في الاصطلاحات الفقرية، ضبط وتخريج: الثبخ خالد عبدالرحمن العلك، بيروت: دار النفائس للطباعـة النشر والتوزيع، الطبعة الأولى. الهواويني، نجيب (منسق)، مجلة الأحكام العدلية، بيروت،

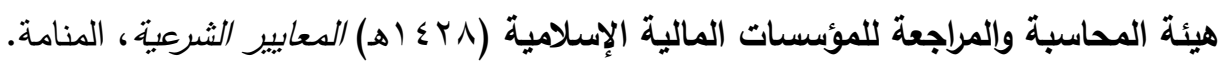
مجلة مجمع الفقه الإسلامي بجدة، بحث الإيجار المنتهي بالتمليك للشاذلي ضدن بحوث العدد الخامس (ع/r) (YT). 


\title{
Leasing Sukuk (Instruments) that is Described in the Disclosure and Ending with Possessing
}

\author{
Abdullah Ibn Muhammaed Al-Omrani \\ Associate Professor \\ The Shari'a College in Riyadh, Saudi Arabia
}

Abstract. This research handles judgments of leasing Sukuk that are described in the disclosure and ending with possessing and Sukuk of property leasing for who sells it in a leasing ending with possessing.

The research has reached the following conclusions:

- It is allowed to lease a property described in a disclosure conditioned that it has the SALAM conditions in it.

- It is allowed to issue a property Sukuk described in the disclosure based on the leasing contract that is described in the disclosure. The source of those Sukuk is considered a seller of the property benefit that is described in the disclosure. The subscribers in them are considered their purchasers. The outcome of the subscription is the price of this benefit. The Sukuk holders own these benefits advantageously or disadvantageously.

It is conditioned that Sukuk issuance contract contains the shari'a (legal) conditions of leasing a property described in the disclosure.

- It is not allowed to pass around Sukuk of property benefit ownership that is described in the disclosure before appointing the property to benefit from except with the regulations of acting on debts.

- It is allowed to issue Sukuk of leasing that is ending with possessing based on the leasing contract, which is a benefit property leasing, and the Shari'a regulations of the leasing contract \& leasing Sukuk are to be observed upon practical application.

- It is allowed to pass around Sukuk of leasing ending with possessing as they represent a common portion of an available property in accordance with standards and Shari'a regulations. 
The contemporary scholars differ with regard to the judgment of leasing for who sells it as a leasing ending with possessing, the predominant is the prohibition, based on this it is not allowed to be shaped as Sukuk or passing it around; as the leasing Sukuk in this dealing are a compound formula of the unreal contracts that lead to usury. 